\title{
Open and Closed Radicals: Local Geometry around Unpaired Electrons Governs Magic-Angle Spinning Dynamic Nuclear Polarization Performance
}

\author{
Gabriele Stevanato, ${ }^{\text {II }}$ Gilles Casano, ${ }^{\text {II }}$ Dominik J. Kubicki, Yu Rao, Laura Esteban Hofer, \\ Georges Menzildjian, Hakim Karoui, Didier Siri, Manuel Cordova, Maxim Yulikov, Gunnar Jeschke, \\ Moreno Lelli, Anne Lesage, Olivier Ouari,* and Lyndon Emsley*
}

Cite This: J. Am. Chem. Soc. 2020, 142, 16587-16599

Read Online

ACCESS | Llll Metrics \& More | 回 Article Recommendations | st Supporting Information

ABSTRACT: The development of magic-angle spinning dynamic nuclear polarization (MAS DNP) has allowed atomic-level characterization of materials for which conventional solid-state NMR is impractical due to the lack of sensitivity. The rapid progress of MAS DNP has been largely enabled through the understanding of rational design concepts for more efficient polarizing agents (PAs). Here, we identify a new design principle which has so far been overlooked. We find that the local geometry around the unpaired electron can change the DNP enhancement by an order of magnitude for two otherwise identical conformers. We present a set of 13 new stable mono- and dinitroxide PAs for MAS DNP NMR where this principle is demonstrated. The radicals are divided into two groups of isomers, named open (O-) and closed (C-), based on the ring conformations in the vicinity of the $\mathrm{N}-\mathrm{O}$ bond. In all cases, the open conformers exhibit dramatically improved DNP performance as compared to the closed counterparts. In particular, a new urea-based biradical named HydrOPol and a mononitroxide $\mathrm{O}-\mathrm{MbPyTol}$ yield enhancements of $330 \pm 60$ and $119 \pm 25$, respectively, at $9.4 \mathrm{~T}$ and $100 \mathrm{~K}$, which are the highest enhancements reported so far in the aqueous solvents used here. We find that while the conformational changes do not significantly affect electron spin-spin distances, they do affect the distribution of the exchange couplings in these biradicals. Electron spin echo envelope modulation (ESEEM) experiments suggest that the improved performance of the open conformers is correlated with higher solvent accessibility.

\section{INTRODUCTION}

Dynamic nuclear polarization (DNP) is a consensus strategy to overcome the well-recognized sensitivity limitations of nuclear magnetic resonance (NMR) experiments. ${ }^{1-3}$ In particular, DNP-induced sensitivity enhancements have been demonstrated in magic-angle-spinning (MAS) NMR experiments on materials samples, ${ }^{4,5}$ such as polymers, ${ }^{6-10}$ porous and structural materials, ${ }^{5,11-16}$ nanoparticles, ${ }^{17-19}$ pharmaceuticals, ${ }^{20-23}$ zeolites, ${ }^{24,25}$ and catalysts, ${ }^{26-33}$ and biomolecular samples $^{34-41}$ in $1 \mathrm{D}$ and $2 \mathrm{D}$ solid-state NMR experiments that are otherwise difficult or unfeasible, even with isotope labeling. DNP in liquid-state experiments has also been shown to yield very substantial ${ }^{13} \mathrm{C}$ enhancements. ${ }^{42-46}$

In DNP experiments, the comparatively high electron polarization is transferred to nuclear spins via microwave irradiation at or close to the electron paramagnetic resonance (EPR) transition. The applied microwave field saturates electron spin transitions that are hyperfine-coupled to nearby nuclear spins. Thereby, the more strongly polarized electron spins can exchange populations with nuclear spins. Several possible mechanisms mediating the transfer have been identified: solid effect (SE), cross effect (CE), thermal mixing $(T M)$, and Overhauser effect $(O E){ }^{47-51}$ The mechanism at play depends on the magnetic field strength, temperature, nuclear and electron spin concentration, and type of polarizing agent (PA). The source of unpaired electrons is vital for efficient DNP and has been the subject of intense recent scrutiny. ${ }^{52}$ With the CE mechanism being typically the most efficient at high magnetic fields and temperatures around $100 \mathrm{~K}$, biradicals have so far proved to be the most efficient polarization source for MAS DNP. ${ }^{53-60}$ The best-performing PAs for high-field DNP are either dinitroxides $54,58,61$ or mixed nitroxide-narrow line radical systems. ${ }^{53,60,62,63}$ High-spin transition metal

Received: May 5, 2020

Published: August 18, 2020 
complexes have also been demonstrated as MAS DNP PAs. ${ }^{64,65}$

Despite this intense development, the best-performing radicals currently deliver ${ }^{1} \mathrm{H}$ DNP enhancements of around $\varepsilon$ $=300$ at $9.4 \mathrm{~T}$ and $100 \mathrm{~K}$ in bulk frozen solutions, ${ }^{54,55,66}$ which is significantly less than the theoretical maximum (corrected for depolarization $\left.{ }^{67,68}\right)$ of $\sim 658$ for ${ }^{1} \mathrm{H}\left(\left|\gamma_{\mathrm{e}} / \gamma_{\mathrm{n}}\right|\right)$. By lowering the temperature to $55 \mathrm{~K}$ or by improving the microwave penetration by adding dielectric particles, enhancement factors close to the theoretical maximum can be obtained with dinitroxides. ${ }^{69,70}$

Over the past decade, a number of design criteria for efficient PAs have been identified and implemented. Initially, TEMPO was used due to its availability, providing a proton enhancement of $\sim 40$ at $9.4 \mathrm{~T}$ at $100 \mathrm{~K}$. In 2004, the use of biradicals with limited flexibility and well-defined inter-electron distances, leading to large dipolar couplings, led to the introduction of the BTnE series $\left({ }^{1} \mathrm{H} \varepsilon \approx 175 \text { at } 84 \mathrm{~K}\right)^{71}$ and TOTAPOL $\left({ }^{1} \mathrm{H} \varepsilon \approx 70\right.$ at $\left.\sim 100 \mathrm{~K}\right) .{ }^{56}$ In 2009 , bTbK was introduced $^{72}\left({ }^{1} \mathrm{H} \varepsilon \approx 250\right.$ at $94 \mathrm{~K}$ and $\left.5 \mathrm{~T}\right)$, which has two TEMPO moieties linked by a rigid tether, leading to a welldefined relative orientation of the nitroxide moieties. This geometrical arrangement translated to more efficient $\mathrm{CE}$ matching, ${ }^{2,3}$ and its theoretical understanding has been recently developed. ${ }^{73}$ A large electron-electron dipolar coupling, essential for $\mathrm{CE}$, is ensured by an average inter-electron distance of $\sim 11.8 \AA$ in this class of radicals. ${ }^{72}$ In 2012, long electron relaxation times were identified as a design criterion, leading to the introduction of bulky substituents on the nitroxides in the $\mathrm{bCTbK}^{21,74}\left({ }^{1} \mathrm{H} \varepsilon \approx 105\right.$ at $\sim 100 \mathrm{~K}$ and $9.4 \mathrm{~T}$ in 1,1,2,2-tetrachloroethane (TCE) and ${ }^{1} \mathrm{H} \varepsilon \approx 60$ at $105 \mathrm{~K}$ and $9.4 \mathrm{~T}$ for microcrystalline glucose and sulfathiazole) and TEKPol $\left({ }^{1} \mathrm{H} \varepsilon>200\right.$ for $16 \mathrm{mM}$ in TCE at $105 \mathrm{~K}$ and $\left.9.4 \mathrm{~T}\right)$ families, ${ }^{55,74,75}$ which are suitable for organic solvents, followed by the water-soluble PyPol $\left({ }^{1} \mathrm{H} \varepsilon \approx 200\right.$ for $10 \mathrm{mM}$ in a water/ glycerol mixture at $97 \mathrm{~K}$ and $9.4 \mathrm{~T})$ and AMUPol $\left({ }^{1} \mathrm{H} \varepsilon \approx 200\right.$ for $10 \mathrm{mM}$ in a water/glycerol mixture at $97 \mathrm{~K}$ and $9.4 \mathrm{~T}$ and ${ }^{1} \mathrm{H} \varepsilon \approx 400$ at $80 \mathrm{~K}$ and $8.9 \mathrm{~T}^{76}$ ) families in $2013 .{ }^{66} \mathrm{In}$ addition, hybrid systems consisting of an isotropic narrow EPR line radical covalently tethered to a broad-line nitroxide moiety have been demonstrated to preserve high enhancements at higher magnetic fields. ${ }^{53,63}$

Here, we introduce and demonstrate the importance of a new design parameter: the local geometry around the unpaired electron. We show that DNP performance is dramatically affected, at both 9.4 and $21.15 \mathrm{~T}$, by changes in local conformation around the unpaired electron in mono- and dinitroxides, for otherwise identical constitution irrespective of the radical concentration. We control the conformation of a tetrahydropyran ring substituent by including locking methyl and phenyl groups. We show that the biradical HydrOPol and the monoradical O-MbPyTol yield enhancements of $330 \pm 60$ and $119 \pm 25$ at $9.4 \mathrm{~T}$ and $100 \mathrm{~K}$ in a dimethyl sulfoxide (DMSO)/water mixture. We use pulsed EPR to identify that, while keeping the mean spin-spin distances and relaxation properties nearly the same, changes in the local geometry lead to differences in solvent accessibility to the electron spin (which is also supported by measured reduction kinetics of the different monoradicals), as well as to differences in the isotropic exchange coupling distributions in biradicals, and in turn correlate with the large differences in DNP performances observed experimentally.

\section{EXPERIMENTAL SECTION}

NMR Spectroscopy. All DNP experiments were performed on a commercial Bruker Avance III $400 \mathrm{MHz}$ NMR spectrometer equipped with a $263 \mathrm{GHz}$ gyrotron microwave source using a 3.2 $\mathrm{mm}$ triple-resonance cross-polarization (CP)-MAS probe at sample temperatures around $100 \mathrm{~K}$ with MAS at $8 \mathrm{kHz}$. All of the radicals were synthesized as reported below and in the Supporting Information (SI). A $3.2 \mathrm{~mm}$ sapphire rotor, to optimize microwave penetration, was filled with $22 \mu \mathrm{L}$ of radical-containing solution. The solution was confined with a silicone plug to prevent any leakage and the rotor closed using either a zirconia or vespel cap. The solvents used were glycerol- $d_{8}: \mathrm{D}_{2} \mathrm{O}: \mathrm{H}_{2} \mathrm{O}(60: 30: 10 \mathrm{v} / \mathrm{v} / \mathrm{v}),{ }^{77}$ DMSO$d_{6}: \mathrm{D}_{2} \mathrm{O}: \mathrm{H}_{2} \mathrm{O}(60: 30: 10 \mathrm{v} / \mathrm{v} / \mathrm{v}),^{78}$ or TCE, ${ }^{21,79}$ commonly used in MAS DNP. Three freeze-thaw cycles were always used to reduce the presence of dissolved oxygen when using $\mathrm{TCE},{ }^{55}$ with each cycle involving the insertion and ejection of the rotor into the stator. The microwave power was optimized for each sample to obtain the largest DNP enhancements. The ${ }^{1} \mathrm{H}$ DNP enhancements of the solvent were measured through ${ }^{1} \mathrm{H}-{ }^{13} \mathrm{C}$ cross-polarization $\left(\varepsilon_{\mathrm{C} C \mathrm{CP}}\right)$ with a standard ramped $(90 \%-100 \%$ or $70 \%-100 \%) \mathrm{CP}$ pulse sequence. ${ }^{80,81}$ In some experiments in which the silicone plug was avoided, the enhancement has been directly measured with a standard proton echo acquisition after a presaturation loop. Details are given in Table S1. In all cases the integrated intensities of the solvent peaks, with and without microwave irradiation, were compared to determine $\varepsilon_{\mathrm{C} \mathrm{CP}}$ in order to account for any line narrowing arising from microwave-induced sample heating.

EPR Spectroscopy. The deuterium electron spin echo envelope modulation (ESEEM) measurements for assessing water accessibility $^{82,83}$ were performed on a Bruker Elexsys E580 EPR spectrometer equipped with a Bruker MS3 split-ring resonator at frequencies of approximately $9.3 \mathrm{GHz}$. The temperature of $50 \mathrm{~K}$ was achieved by liquid helium cooling. A $3 \mathrm{~mm}$ o.d. capillary loaded with roughly $60 \mu \mathrm{L}$ sample was inserted into the resonator after shockfreezing in liquid nitrogen. Three-pulse ESEEM measurements consist of the following sequence of pulses: $\pi / 2-\tau-\pi / 2-T-\pi / 2-\tau$-echo. The longitudinal electron magnetization is converted into transverse magnetization on allowed electron spin and nominally forbidden electron-nuclear spin transitions by the first $\pi / 2$ pulse. During the first delay $\tau$, electron transverse magnetization dephases, and the second $\pi / 2$ pulse flips most of the magnetization back to the $z$ axis. Part of the magnetization is converted to transverse magnetization on nuclear transitions. Longitudinal relaxation and transverse nuclear spin relaxation occur during time $T$, and the final $\pi / 2$ pulse converts longitudinal electron spin magnetization and transverse nuclear magnetization into transverse magnetization on allowed and forbidden transitions. An echo signal is observed at time $T+2 \tau$. The value of $\tau=344$ ns was used in order to suppress ${ }^{1} \mathrm{H}$ modulations on the ESEEM decay envelope. The second inter-pulse delay, $T$, with an initial value of $80 \mathrm{~ns}$ was incremented in steps of $8 \mathrm{~ns}$. The integrated echo intensity was measured as a function of $T$ increment, with an integration gate of $32 \mathrm{~ns}$ length. The pulse lengths were $16 \mathrm{~ns}$ for the $\pi / 2$ pulse and 32 ns for the $\pi$ pulse.

Echo-detected (ED) EPR measurements, as well as longitudinal and transverse relaxation measurements, were performed at $\mathrm{W}$ band $(94.1 \mathrm{GHz})$ on a Bruker Elexsys E680 spectrometer at $105 \mathrm{~K}$. Transverse relaxation data were acquired with a Hahn echo sequence, $\pi / 2-t-\pi$-t -echo, and applying a $(+x,-x)$ phase cycle to the $\pi / 2$ pulse. Longitudinal relaxation data were acquired with an inversion recovery pulse sequence, $\pi$-T- $\pi / 2-t-\pi-t$-echo, with a $(+x,-x)$ phase cycle on the $\pi / 2$ pulse. The pulse lengths were $12 \mathrm{~ns}$ for the $\pi / 2$ pulses and 24 ns for the $\pi$ pulse of the detection echo subsequence and for the inversion pulse. Initial values of $1 \mu \mathrm{s}$ for $T$ and $400 \mathrm{~ns}$ for $t$ were used.

Molecular Dynamics Simulations. In order to correlate molecular structures with the DNP efficiencies, molecular dynamics simulations were carried out in explicit water for the O-radicals ( 2 and 7) and their C-counterparts ( $\mathbf{3}$ and $\mathbf{8}$ ) as described in detail in the SI, section 9. The simulations were done for 300 ps trajectories in a cubic 
box with about 1400 water molecules using the GROMACS package using an AMBER force field (ff99SB).

Synthesis of the Radicals. Experimental details of synthetic procedures and characterization of all compounds are given in the SI. The mononitroxides were prepared according to Scheme 1, starting

Scheme 1. Synthesis of the O-, C-, and O/C-Isomers of MbPyTol and MPhTO Nitroxides

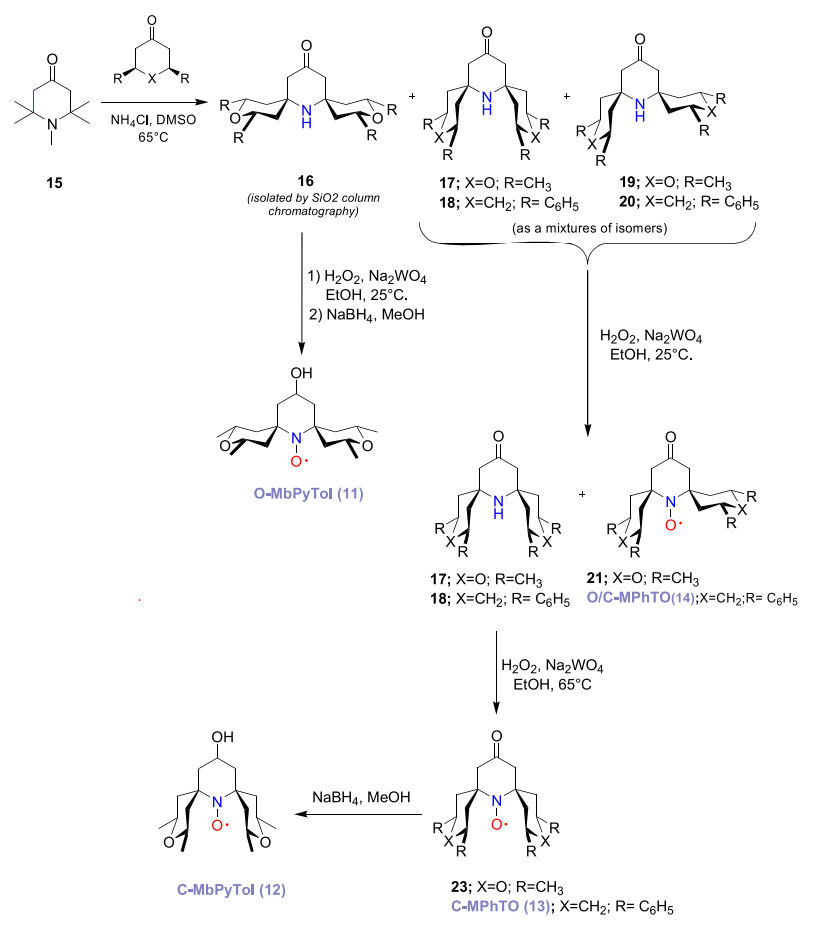

from the corresponding pure cis-2,4,10,12-tetramethyl-7-aza-3,11dioxadispiro[5.1.5.3] hexadecan-15-one isomers 15, 16, and 18, previously obtained by reacting 1,2,2,6,6-pentamethylpiperidine (14) with cis-2,6-dimethyltetrahydropyran-4-one in the presence of ammonium chloride via crossed aldol condensation (Scheme 1). During the reaction, the three isomers, namely open (O-), closed (C), and open/closed (O/C-), are formed and isolated by column chromatography either at the amine stage or after oxidation to the corresponding nitroxide (see SI). The same procedure was followed the preparation of 17 and 19 but using cis-3,5-diphenylcyclohexanone. The conformations have been determined by X-ray structure analysis of compounds 11, 12, 13, 15, 16, 17, 21, and 22 (Figures S16-S19). The dinitroxides were prepared using the previously reported procedures $^{54,66}$ starting from mononitroxides 20-22.

\section{RESULTS AND DISCUSSION}

Open and Closed Conformers. Figure 1 shows all the radicals investigated in this work. In AMUPol ${ }^{66}(\mathbf{1})$, the spirotetrahydropyran rings at the $\alpha$-position of the nitroxide moiety can exist in two different chair conformations: pointing away from the $\mathrm{NO}^{\bullet}$ bond (denoted as open, $\mathrm{O}-$ ) or pointing toward the $\mathrm{NO}^{\bullet}$ bond (denoted as closed, $\mathrm{C}$-). Given the energy barrier for interconversion and the relative energies of the two states, AMUPol exists in solution as a mixture of these two populations of conformers (Scheme 2).

Interconversion between the two conformers in AMUPol is rapid at room temperature, and the two conformers cannot be isolated. In the new biradicals $\mathbf{2 - 8}$, the conformation of the tetrahydropyran (THP) rings is locked by the introduction of cis- $\mathrm{CH}_{3}$ groups in positions 2 and 6 . The conformation with two synaxial methyl groups is energetically unfavorable and does not contribute appreciably; therefore, only the conformations with the two methyl groups in the equatorial positions are observed. By fixing the absolute configuration of the asymmetric carbon atoms 2 and 6 , it is possible to fix the conformation of the THP rings in the biradicals $\mathbf{2 - 8}$, generating molecules with open (O-) and closed (C-) conformations around the nitroxide moiety. In particular, we synthesized and isolated three diastereoisomeric meso forms: the first, with the THP 2 and 6 positions with configuration $S, R, S, R$, has the two THP rings in an open conformation (O-); conversely, when the configuration is $R, S, R, S$, a second diastereoisomer with the THP rings in a closed conformation (C-) is generated. The third diastereoisomer synthesized has a configuration $S, R, R, S$ or $R, S, S, R$, with the two THP rings one in the open and the other in the closed conformation (O/C-). Following synthesis, the different $\mathrm{O}$ - and $\mathrm{C}$-conformers can be separated by silica chromatography, and the conformations were determined by $\mathrm{X}$-ray structure analysis (Figures S16-S19). There is no conformational exchange between the $\mathrm{O}$ - and $\mathrm{C}$-conformers because they are diastereomers, as shown by liquid-state NMR spectra of their reduced forms (see SI for details). We have synthesized $\mathrm{O}$ - and $\mathrm{C}$-dinitroxides with two different types of backbone (AMUPol, 2-6; PyPol, 7, 8) and different lengths of polyethylene glycol (PEG) chains (4 units, 2-4; 2 units, 5, 6). We further demonstrate the validity of the new design principle by investigating mononitroxides with either methyl $(11,12)$ or phenyl $(13,14)$ groups as locking substituents. The possible role of deuterated methyl groups is considered by comparing 10 to 11 .

Room-Temperature EPR Characterization. In order to characterize the local structure of the paramagnetic centers in the new radicals, we performed room-temperature X-band (9.4 $\mathrm{GHz}, 0.35 \mathrm{~T}$ ) continuous-wave (CW) EPR experiments of 100 $\mu \mathrm{M}$ solutions in either TCE, water or acetonitrile as reported in Figure 1 (third column). All of the biradicals show a complex splitting pattern in solution resulting from an interplay of hyperfine coupling to ${ }^{14} \mathrm{~N}$ of the nitroxide $\left(A_{\text {iso }}\right)$ and the exchange interaction $(J)$ between the two unpaired electrons. The solution-state EPR data in Figure 1 were fitted as described in the SI, section 10, assuming a Gaussian distribution (with standard deviation $\sigma(J)$ ) of exchange couplings and the exchange Hamiltonian expressed as $J \cdot \boldsymbol{S}_{1} \cdot \boldsymbol{S}_{2}$. (We note that another convention exists for which the exchange Hamiltonian is $-2 J \cdot S_{1} \cdot S_{2}$, resulting in only half of the value for $|J| ;{ }^{60}$ see SI section 10.)

The EPR spectrum of O-MAMUPol (2) can be fitted with $A_{\text {iso }} \approx 44.7 \mathrm{MHz},|J|=48.0 \pm 2.0 \mathrm{MHz}$, and the width of the $J$ coupling distribution, $\sigma(J)$, of about $8 \mathrm{MHz}$. It is characterized by $|J| \approx A_{\text {iso }}$, in which case up to 15 EPR lines could be observed. ${ }^{54}$

For C-MAMUPol (3), the spectrum can be fitted with $A_{\text {iso }} \approx$ 43.0 MHz, $|J|=0 \mathrm{MHz}$, and $\sigma(J)=150 \mathrm{MHz}$. Molecular dynamics simulations in SI section 9 also show a different distribution of exchange couplings between 2 and 3, with conformations characterized by $|J|>A_{\text {iso }}$ in 3 that are absent for 2. Low-temperature ED EPR spectra are also consistent with weaker and better-defined J-coupling for O-MAMUPol (2) and stronger and broadly distributed J-couplings for CMAMUPol (3) (see SI section 10).

For O/C-MAMUPol (4), the fit yields $A_{\text {iso }}=44.7 \mathrm{MHz},|J|=$ $110.0 \pm 5 \mathrm{MHz}$, and $\sigma(J)=12 \mathrm{MHz}$. This biradical is characterized by $|J|>A_{\text {iss }}$. 


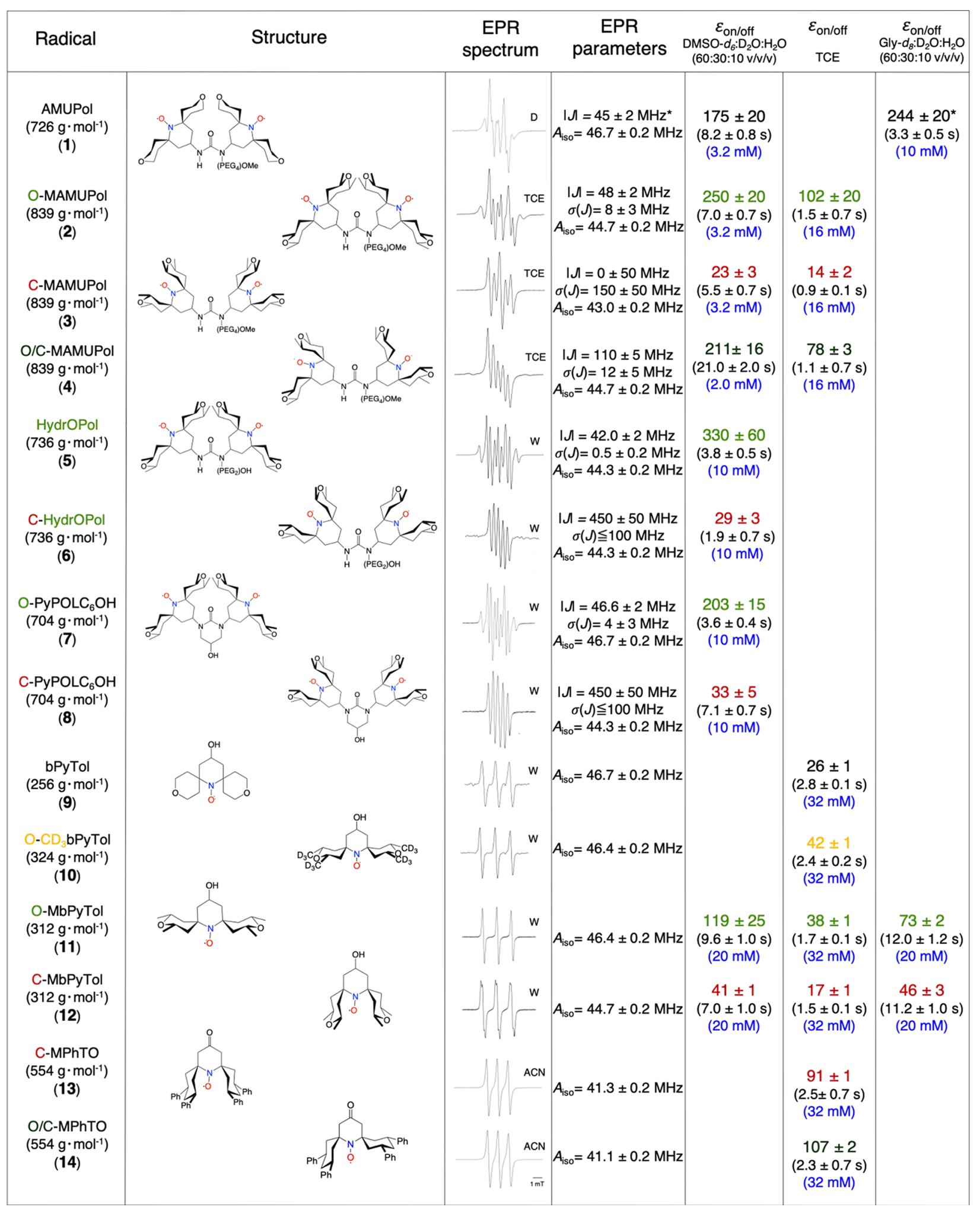

Figure 1. Radicals investigated in this work. Column 1 shows the abbreviations and molecular weights, column 2 the molecular structures, column 3 the room-temperature X-band EPR spectra $[\sim 0.1 \mathrm{mM}$ in 1,1,2,2-tetrachloroethane (TCE), water (w), acetonitrile (ACN), or DMSO$\left.d_{6}: \mathrm{D}_{2} \mathrm{O}: \mathrm{H}_{2} \mathrm{O}(60: 30: 10) \mathrm{v} / \mathrm{v} / \mathrm{v}(\mathrm{D})\right]$, and column 4 the room-temperature X-band EPR exchange coupling $J$, corresponding distribution $\sigma(J)$, and isotropic hyperfine $A_{\text {iso }}$ parameters, extracted from fitting analysis detailed in the SI, section 10 . An exchange coupling Hamiltonian $J S_{1} \cdot S_{2}$ was used. (Note that another convention exists that leads to only half the value for $|J|$.) See SI for a discussion of the sign. Columns 5-7 show MAS DNP enhancements, polarization build-up times (in black), and concentration (in blue) measured at $9.4 \mathrm{~T}$ and $100 \mathrm{~K}$ in DMSO- $d_{6}: \mathrm{D}_{2} \mathrm{O}: \mathrm{H}_{2} \mathrm{O}(60: 30: 10$ $\mathrm{v} / \mathrm{v} / \mathrm{v}$ ) (column 5), in TCE (column 6), and in glycerol- $d_{8}: \mathrm{D}_{2} \mathrm{O}: \mathrm{H}_{2} \mathrm{O}(60: 30: 10 \mathrm{v} / \mathrm{v} / \mathrm{v})$ (column 7). PEG $=-\mathrm{CH}_{2} \mathrm{CH}_{2} \mathrm{O}-$. The prefixes $\mathrm{O}$ (green), C- (red), and O/C- (dark green) indicate open, closed, and open/closed, conformers, respectively. Values marked with an asterisk $(*)$ are EPR parameters, MAS DNP enhancement, and build-up time from ref 54 . 
Scheme 2. Conformational Analysis ${ }^{a}$

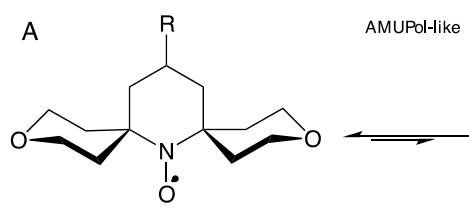

Open Conformation (O)

B

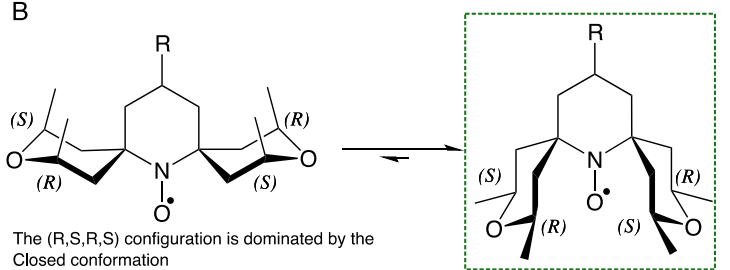
Closed conformation

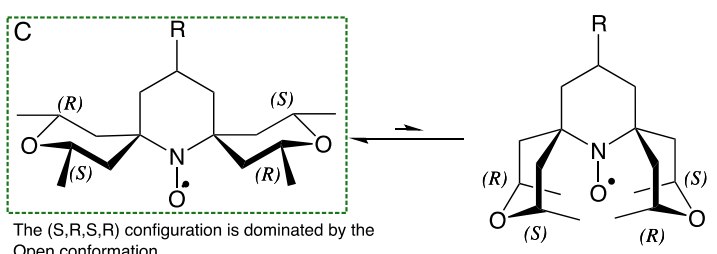
Open conformation

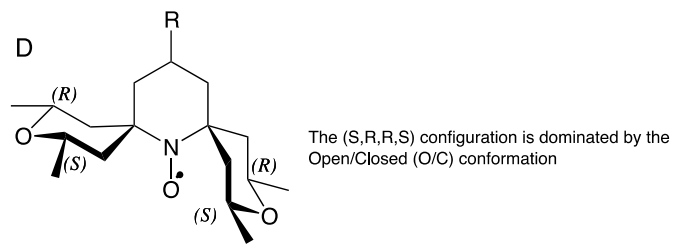

${ }^{a}$ Panel A shows the conformational equilibrium active in each nitroxide moiety of the AMUPol biradical. By introducing cis-2,6dimethyl groups in the tetrahydropyran ring, is possible to lock the conformational equilibrium, favoring the conformation where the ring substituents assume equatorial positions. Reading clockwise the absolute configuration in panels $\mathrm{B}-\mathrm{D}$, we show that the $(R, S, R, S)$ configuration corresponds to a closed conformation (panel $B$ ), the $(S, R, S, R)$ configuration to an open form (panel C), and the $(S, R, R, S)$ configuration to a mixed open/closed conformation (panel D).

HydrOPol $(5)\left(A_{\text {iso }}=44.3 \mathrm{MHz},|J|=42.0 \pm 2 \mathrm{MHz}\right.$, and $\sigma(J)=0.5 \mathrm{MHz})$ is in a similar regime to 2 , with $|J| \approx A_{\text {iso }}$ but characterized by a smaller distribution of $J$.

C-HydrOPol (6) $\left(A_{\text {iso }}=44.3 \mathrm{MHz},|J|=450 \pm 50 \mathrm{MHz}\right.$, and $\sigma(J) \leq 100 \mathrm{MHz})$ has $|J| \gg A_{\text {iso }}$ with a relatively broad distribution of $J$.

Similarly, O-PyPolC 6 OH (7) $\left(A_{\text {iso }}=46.7 \mathrm{MHz},|J|=46.6 \pm\right.$ $2.0 \mathrm{MHz}$, and $\sigma(J)=4 \mathrm{MHz})$ and $\mathrm{C}-\mathrm{PyPolC}_{6} \mathrm{OH}(8)\left(A_{\text {iso }}=\right.$ $44.3 \mathrm{MHz},|J| \gtrsim 400 \mathrm{MHz}$, and $\sigma(J) \leq 100 \mathrm{MHz}$ ) belong to the $|J| \approx A_{\text {iso }}$ and $|J| \gg A_{\text {iso }}$ regimes, respectively.

The EPR spectra of the mononitroxides are all characterized by a $1: 1: 1$ triplet resulting from the hyperfine coupling to ${ }^{14} \mathrm{~N}$ with the following fitted values: bPyTol (9), reference for 1014, $A_{\text {iso }}=46.7 \mathrm{MHz}$; O-CD 3 bPyTol (10), $A_{\text {iso }}=46.4 \mathrm{MHz}$; OMbPyTol (11), $A_{\text {iso }}=46.4 \mathrm{MHz}$; C-MbPyTol (12), $A_{\text {iso }}=44.7$ $\mathrm{MHz}$; C-MPhTO (13), $A_{\text {iso }}=41.3 \mathrm{MHz}$; and O/C-MPhTO (14), $A_{\text {iso }}=41.1 \mathrm{MHz}$. In C-MbPyTol (12) each line is further split, both for the CW room-temperature EPR spectrum in water (Figure 1) and in $\mathrm{D}_{2} \mathrm{O}$ (see Table S7 and Figure S37). We attribute this additional splitting to a hyperfine interaction between the electron spin and two axial or equatorial proton spins of the central ring (SI section 10).
MAS DNP Performance. We observe a stark difference in MAS DNP performance between C- and O-isomers for each pair in the series despite their otherwise identical constitution. Figure 1 shows the ${ }^{1} \mathrm{H}$ MAS DNP solvent enhancements $\left(\varepsilon_{\mathrm{C} \mathrm{CP}}\right.$ or $\varepsilon_{1 \mathrm{H}}$ for 9-12 in TCE) obtained in DMSO$d_{6}: \mathrm{D}_{2} \mathrm{O}: \mathrm{H}_{2} \mathrm{O}(60: 30: 10 \mathrm{v} / \mathrm{v} / \mathrm{v})$ at $\sim 100 \mathrm{~K}, 9.4 \mathrm{~T}$, and $8 \mathrm{kHz}$ MAS rate for the following radical concentrations: $3.2 \mathrm{mM}$, OMAMUPol (2) and C-MAMUPol (3); $2 \mathrm{mM}, \mathrm{O} / \mathrm{C}$ MAMUPol (4); $10 \mathrm{mM}$, HydrOPol (5), C-HydrOPol (6), $\mathrm{O}-\mathrm{PyPolC}_{6} \mathrm{OH}(7)$, and $\mathrm{C}-\mathrm{PyPolC}_{6} \mathrm{OH}(8)$; and $20 \mathrm{mM}$,

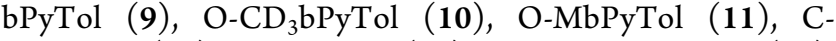
MbPyTol (12), C-MPhTO (13), and O/C-MPhTO (14). DMSO- $d_{6}: \mathrm{D}_{2} \mathrm{O}: \mathrm{H}_{2} \mathrm{O}$ was used for comparison across the whole series because of otherwise generally lower solubility for some in glycerol- $d_{8}: \mathrm{D}_{2} \mathrm{O}: \mathrm{H}_{2} \mathrm{O}$.

The biradicals $\mathbf{2}$ and $\mathbf{3}$, having an identical urea-based linker and differing only in the conformation of the tetrahydropyran rings, represent the $\mathrm{O}$ - and $\mathrm{C}$-conformers most closely related to AMUPol (1). MAS DNP experiments were performed at a concentration of $3.2 \mathrm{mM}$ (dictated by the poor solubility of the $\mathrm{C}$-conformer in the $\mathrm{DMSO} /$ water solvent mixture). An order of magnitude difference in the measured $\varepsilon_{\mathrm{C} C \mathrm{CP}}$ is observed: 250 \pm 20 for 2 and $23.0 \pm 2.5$ for 3 (see Figure 1, column 5). For comparison, AMUPol (1) at $3.2 \mathrm{mM}$ in the same solvent mixture, field, and temperature yields an $\varepsilon_{\mathrm{C} C \mathrm{CP}}=175 \pm 20$ (and at $10 \mathrm{mM}$ the enhancement we obtain is $\left.\varepsilon_{\mathrm{C}} \mathrm{CP}=183 \pm 20\right)$. In addition, O/C-MAMUPol (4) yields at $2 \mathrm{mM}$ an $\varepsilon_{\mathrm{C} \mathrm{CP}}=211$ \pm 16 (see Figure 1, column 5).

In order to address whether this difference in DNP enhancement is solvent specific, we have investigated alternative DNP matrices (Figure 1, columns 6 and 7). All solvent mixtures investigated are routinely used in MAS DNP experiments and known to form good glass at cryogenic temperatures. ${ }^{79}$ Specifically, 2 and 3 have been tested at 16 $\mathrm{mM}$, the optimal concentration for the TEKPol radical family, $^{55}$ in $\mathrm{TCE}^{79}$ returning $\varepsilon_{\mathrm{C} \text { CP }}=102 \pm 20$ for 2 and $\varepsilon_{\mathrm{C} \mathrm{CP}}=14 \pm 2$ for 3 , confirming the difference of almost 1 order of magnitude in the MAS DNP results between $\mathrm{O}$ - and C-conformers. O/C-MAMUPol (4) at $16 \mathrm{mM}$ in TCE yields $\varepsilon_{\mathrm{C} \mathrm{CP}}=78 \pm 3$, which is in between the values for 2 and 3 . It has been reported that the overall ${ }^{1} \mathrm{H}$ concentrations in TCE and in glycerol- $d_{8}: \mathrm{D}_{2} \mathrm{O}: \mathrm{H}_{2} \mathrm{O}(60: 30: 10 \mathrm{v} / \mathrm{v} / \mathrm{v})$ or DMSO$d_{6}: \mathrm{D}_{2} \mathrm{O}: \mathrm{H}_{2} \mathrm{O}(60: 30: 10 \mathrm{v} / \mathrm{v} / \mathrm{v})$ are identical. ${ }^{79}$ As reported in Table S2, at $21.15 \mathrm{~T}, 16 \mathrm{mM} 4$ in TCE shows a better enhancement than the widely used TEKPol at the same concentration $(9.7 \pm 1.0$ versus $6.5 \pm 0.5)$. The $\sim 50 \%$ difference in enhancement between DMSO- $d_{6}: \mathrm{D}_{2} \mathrm{O}: \mathrm{H}_{2} \mathrm{O}$ $(60: 30: 10 \mathrm{v} / \mathrm{v} / \mathrm{v})$ and TCE for both 2 and 3 can be due to the different conformations assumed by the radicals in different solvents, but also to the tendency of urea moieties to interact through complementary hydrogen bonds, thus potentially favoring aggregation processes in TCE, as described for the urea-based series in ref 55 .

$\mathrm{HydrOPol}(\mathbf{5})$ is the open methylated conformer equivalent of PyPolPEG $\mathrm{OH}_{2} \mathrm{OH}$, which yielded $\varepsilon_{\mathrm{C} \mathrm{CP}}=303$ at $10 \mathrm{mM}$ in glycerol- $d_{8}: \mathrm{D}_{2} \mathrm{O}: \mathrm{H}_{2} \mathrm{O}(60: 30: 10 \mathrm{v} / \mathrm{v} / \mathrm{v})$ in ref 54 . Here, 5 dissolved in DMSO- $d_{6}: \mathrm{D}_{2} \mathrm{O}: \mathrm{H}_{2} \mathrm{O}(60: 30: 10 \mathrm{v} / \mathrm{v} / \mathrm{v})$ at $10 \mathrm{mM}$ and measured under otherwise identical field and temperature conditions results in a similar proton enhancement, $\varepsilon_{\mathrm{C} \mathrm{CP}}=$ 330. The closed analogue $\mathrm{C}-\mathrm{HydrOPol}(6)$ dissolved at 10 $\mathrm{mM}$ in identical DMSO/water solvent yielded an order of magnitude smaller enhancement $\left(\varepsilon_{\mathrm{C} \mathrm{CP}}=29 \pm 3\right)$ at $9.4 \mathrm{~T}$ and $100 \mathrm{~K}$. The corresponding Zeeman field profile for 5 at $9.4 \mathrm{~T}$ 
and $100 \mathrm{~K}$ is reported in Figure S29. The difference between positive and negative DNP peaks is approximately $0.025 \mathrm{~T}$, corresponding, in electron frequency units, to $1.57 \nu_{\mathrm{H}}$, with $\nu_{\mathrm{H}}$ the ${ }^{1} \mathrm{H}$ Larmor frequency at $9.4 \mathrm{~T}$. We have also conducted experiments on 5 at $5 \mathrm{mM}$ using a $1.3 \mathrm{~mm}$ MAS DNP probe enabling fast MAS up to $40 \mathrm{kHz}$ under cryogenic DNP conditions. In this case a proton enhancement of $\varepsilon_{1 \mathrm{H}}=293$ at $8 \mathrm{kHz}$ was measured (see Table S3 and Figure S31). This enhancement was further improved to $\varepsilon_{1 \mathrm{H}}=350$ upon addition of manually ground sapphire particles. ${ }^{84}$

$\mathrm{O}-\mathrm{PyPolC}_{6} \mathrm{OH}(7)$ and $\mathrm{C}-\mathrm{PyPolC}_{6} \mathrm{OH}(8)$ are the O- and $\mathrm{C}$-conformers of $\mathrm{PyPolC}_{6} \mathrm{OH}$, which yielded $\varepsilon_{\mathrm{C}} \mathrm{CP}=290$ in glycerol- $d_{8}: \mathrm{D}_{2} \mathrm{O}: \mathrm{H}_{2} \mathrm{O}(60: 30: 10 \mathrm{v} / \mathrm{v} / \mathrm{v})$ at $10 \mathrm{mM}$ in ref 54 . Here, 7 and 8 dissolved in DMSO- $d_{6}: \mathrm{D}_{2} \mathrm{O}: \mathrm{H}_{2} \mathrm{O}(60: 30: 10 \mathrm{v} /$ $\mathrm{v} / \mathrm{v})$ at $10 \mathrm{mM}$ and measured under otherwise identical field and temperature conditions yield $\varepsilon_{\mathrm{C} C P}=203 \pm 15$ and $\varepsilon_{\mathrm{C} C \mathrm{CP}}=$ $33 \pm 5$, respectively. The results for 7 and 8 correlate with the previous observations for $\mathbf{2}$ and $\mathbf{3}$ in the same solvent (see Figure 1), confirming an almost 1 order of magnitude MAS DNP enhancement difference between the $\mathrm{O}$ - and C-classes.

A common adverse feature to many PAs is the reduced overall contribution to the NMR signal intensity due to paramagnetic bleaching caused by the PA itself. ${ }^{67,68,85}$ In some cases, the bleaching is aggravated as the MAS rate is increased, leading to the so-called depolarization curve. ${ }^{63,67}$ We have determined the contribution factors at static and $12 \mathrm{kHz}$ MAS rates using a $3.2 \mathrm{~mm}$ sapphire rotor for some of the investigated radicals $(\mathbf{1}, \mathbf{5}, \mathbf{1 1}, \mathbf{1 2})$ in $\mathrm{DMSO} /$ water mixture at $9.4 \mathrm{~T}$ and $100 \mathrm{~K}$. The values are detailed in Table S4. The contribution factor for biradicals $\mathbf{1}$ and $\mathbf{5}$ in a static sample, $\theta_{\mathrm{s}}$, ranges in between 0.87 and 0.88 , whereas at $12 \mathrm{kHz}, \theta_{12}$, it ranges from 0.51 and 0.44 . For the monoradicals 11 and 12 at $20 \mathrm{mM}, \theta_{\mathrm{s}}$ is 0.91 and 0.95 , with $\theta_{12}$ of 0.41 and 0.52 , respectively. The decreasing value of $\theta$ with the MAS rate is indicative of depolarization effects, as expected for this type of nitroxide radicals if the DNP mechanism is CE. ${ }^{67}$ In the case of monoradicals 11 and 12 at $20 \mathrm{mM}$, the reduction of the contribution factor with the MAS rate is rationalized in terms of intermolecular $\mathrm{CE}$ as discussed below.

It has recently been shown that the interplay between dipolar and exchange interactions, together with the mutual $g$ tensor orientation, is crucial for the PA efficiency, with the balance between dipolar and exchange coupling being predicted to play an important role at high magnetic fields. ${ }^{53,59-61,73}$

We have carried out MD simulations in explicit water, as detailed in SI section 9, in order to estimate the relative orientations of the nitroxide moieties in open and closed forms. As expected for the linkers used here, the mean angles observed in the simulations for 2 and 3 and for 7 and 8 between the NO tensors exclude any collinearity that would result in no DNP. Figure S36 shows only a small change in the relative $g$ tensor orientations between $\mathrm{O}$ - and $\mathrm{C}$-isomers (e.g., from $\langle\theta\rangle=138 \pm 11^{\circ}$ for O-MAMUPol (2) (Figure S36a) to $\langle\theta\rangle=149 \pm 12^{\circ}$ for C-MAMUPol (3) (Figure S36b) and from $\langle\theta\rangle=126 \pm 11^{\circ}$ for $\mathrm{O}-\mathrm{PyPolC}_{6} \mathrm{OH} 7$ (Figure S36e) to $\langle\theta\rangle=$ $140 \pm 13^{\circ}$ for $\mathrm{C}-\mathrm{PyPolC}_{6} \mathrm{OH}(8)$ (Figure S36f)), which does not correlate with the large MAS DNP differences experimentally observed.

With regard to the performance at higher fields, at $21.15 \mathrm{~T}$ the ${ }^{1} \mathrm{H}$ enhancement of 5 at $10 \mathrm{mM}$ drops, as expected, to around 10. Noticeably, as reported in Figure S30 and Table S2, at $21.15 \mathrm{~T}, 8 \mathrm{kHz}$ MAS, and in DMSO- $d_{6}: \mathrm{D}_{2} \mathrm{O}: \mathrm{H}_{2} \mathrm{O}(60: 30: 10$ v/v/v), $2 \mathrm{mM}$ HydrOPol (5) yields a factor $\sim 4$ better MAS DNP enhancement than C-HydrOPol (6) (21.6 \pm 5.5 vs $4.3 \pm$ $0.6)$. The better performance reduces to a factor of $\sim 3(9.7 \pm$ 1.0 vs $3.2 \pm 0.3)$ at $10 \mathrm{mM}$ under the same conditions of solvent and magnetic field. This similar behavior would suggest that there is no big change in the magnetic interactions for 5 and $\mathbf{6}$ in frozen solution.

AMUPol (1) in glycerol/water mixtures, for example, yields proton enhancements that change from 20 to 250 in between 21.15 and $9.4 \mathrm{~T}$. We note that $\mathrm{M}$-TinyPol, the $\mathrm{O}$-analogue of TinyPol, has recently shown a remarkable proton enhancement of 32 and 90 at $10 \mathrm{mM}$ and $100 \mathrm{~K}$ at 21.15 and $18.8 \mathrm{~T}$, respectively. M-TinyPol and AMUPol (1) have similar exchange values, i.e., $|J| \approx 30 \mathrm{MHz}$, but different dipolar interactions. $^{61}$

In the biradical series $\mathbf{1 - 8}$, the measured exchange interaction from room-temperature solution-state $\mathrm{CW} \mathrm{X}$ band EPR for two of the closed radicals ( 6 and 8 ) is up to an order of magnitude higher than that for the open analogues. Specifically, for C-MAMUPol (3) and O-MAMUPol (2), the measured $J$ value changes from a distribution of $0 \pm 50 \mathrm{MHz}$ to $48 \pm 2 \mathrm{MHz}$. In contrast, for $\mathrm{HydrOPol}$ (5) and CHydrOPol (6), the measured $J$ value changes from a distribution of $42 \pm 2 \mathrm{MHz}$ to $450 \pm 50 \mathrm{MHz}$. The result is similar for the pair 7 and $\mathbf{8}$. However, these room-temperature solution-state values should be interpreted with caution. In solution at room temperature, it is possible that the conformational dynamics leads to rare instances where the two nitroxide groups are in very close proximity, which could lead to extremely large instantaneous $J$ values and large average $J$ values. The sterics of the open and closed forms are such that this is much less likely to occur in the open isomers. This could lead to a very large average $J$ coupling in solution, which would not be representative of the conformations present in frozen solutions. We note also that the MD simulations (see Figure S34) do not predict, for O-MAMUPol (2) and C-MAMUPol (3), any large conformational changes that would lead to these extreme $J$ values. In Figure S34 we see a modest shift to slightly higher predicted $J$ couplings in the closed isomers and to a slightly broader distribution of couplings. This is in line with the room-temperature solution-state EPR measurements for this pair.

The usually reported matching condition for CE, e.g., $\omega_{01}-$ $\omega_{02}= \pm \omega_{0 \mathrm{n}}$ with $\omega_{01}, \omega_{02}$ electron frequencies and $\omega_{0 \mathrm{n}}$ nuclear Larmor frequency, assumes that $D=-(d+J) \ll \omega_{0 \text { n }}$ with $d$ and $J$ being the electron-electron dipole and exchange interactions, respectively. The $d$ value for AMUPol (1) is of the order of $30 \mathrm{MHz}$ and is presumably similar for the other biradicals here (see, for example, Table S6 and Figure S36c,d for O-MAMUPol (2) and C-MAMUPol (3) and Figure S36g,h for $\mathrm{O}-\mathrm{PyPolC}_{6} \mathrm{OH}(7)$ and $\mathrm{C}-\mathrm{PyPolC}_{6} \mathrm{OH}(8)$ extracted from the $\mathrm{MD}$ trajectories). The average solution-state $|J|$ value for the C-radical $\mathbf{6}$ and $\mathbf{8}$ is estimated from room-temperature EPR data to be the same order of magnitude as $\omega_{0 \mathrm{H}}$ at $9.4 \mathrm{~T}$ and would then be predicted to yield relatively much better performance at higher magnetic fields. However, as shown in Figure S30 and Table S2, HydrOPol (5) at 21.15 T and at different concentrations still performs better than $\mathrm{C}-\mathrm{HydrOPol}$ (6).

As a result, we conclude that the $J$ couplings in frozen solution are more likely to be in line with the predictions from the MD simulations, and that the very large measured solutionstate values are not relevant to the DNP conditions here. 
Measuring the $J$ values and their distributions through a multifield EPR study is out of the scope here and will be the subject of further work.

The small predicted changes in the $J$ couplings for $\mathbf{2}$ and $\mathbf{3}$ could nevertheless partially explain its relatively poorer MAS DNP results at $9.4 \mathrm{~T}^{86}$

Here, in order to exclude that the difference in the MAS DNP enhancement between $\mathrm{O}$ - and $\mathrm{C}$-conformers is exclusively $J$-related, we have investigated the monoradicals 9-14, where intramolecular $J$ interactions are absent. The open monoradical O-MbPyTol (11) at $20 \mathrm{mM}, 9.4 \mathrm{~T}$, and 100 K yields an exceptional $\varepsilon_{\mathrm{C} C \mathrm{CP}}=119 \pm 25$, which is a factor of $\sim 3$ higher than that of the closed analogue C-MbPyTol (12), $\varepsilon_{\mathrm{C} \mathrm{CP}}=41 \pm 1$ in $\mathrm{DMSO} /$ water mixture. We note that this is by far the highest enhancement so far reported for a mononitroxide under these conditions.

The trend for monoradicals is confirmed as O-MbPyTol (11), at $16 \mathrm{mM}$ in TCE (see also Figure S32 for sample temperature), yields an $\varepsilon_{1 \mathrm{H}}=38 \pm 1$, and yields $73 \pm 2$ at 20 $\mathrm{mM}$ in a glycerol/water mixture, whereas C-MbPyTol (12), at $16 \mathrm{mM}$ in TCE, yields an $\varepsilon_{1 \mathrm{H}}=17 \pm 1$, and yields $46 \pm 3$ at 20 $\mathrm{mM}$ in a glycerol/water mixture.

Remarkably, despite the absence of exchange coupling, a significant difference in MAS DNP efficiency between $\mathrm{O}$ - and C- persists across different solvents for the monoradicals. We note that the factor of $\sim 2-3$ between 11 and 12, in different solvents, does not match the factor of $\sim 10$ between 2 and 3, 5 and 6, or 7 and 8. For mononitroxides the DNP mechanism is expected to be mostly SE at low radical concentration, and it is expected to have an increasing contribution from intermolecular CE with increasing radical concentration.

We have subsequently tested the concentration dependence of the DNP enhancement for 11 and 12. Figure 2 shows the

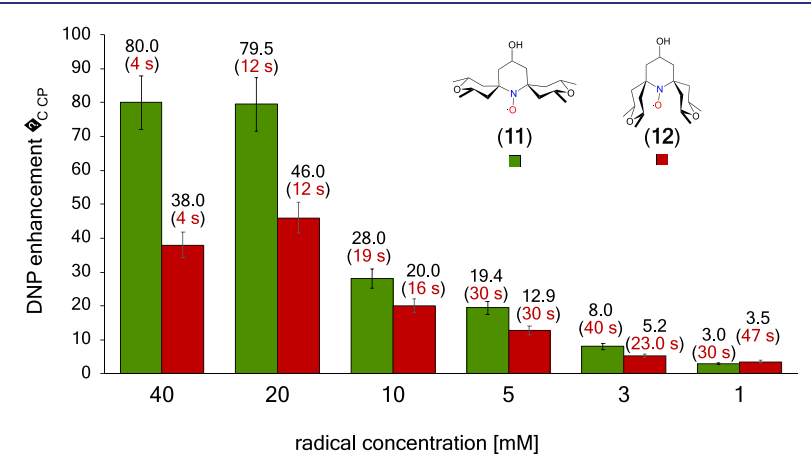

Figure 2. ${ }^{1} \mathrm{H}$ MAS DNP enhancements measured via ${ }^{1} \mathrm{H}-{ }^{13} \mathrm{C} \mathrm{CP}$ for the monoradicals O-MbPyTol (11 in green) and C-MbPyTol (12 in red) in DMSO- $d_{6}: \mathrm{D}_{2} \mathrm{O}: \mathrm{H}_{2} \mathrm{O}(60: 30: 10 \mathrm{v} / \mathrm{v} / \mathrm{v})$ at different radical concentrations at $9.4 \mathrm{~T}$ and $100 \mathrm{~K}$. The observed $\varepsilon_{\mathrm{C} C \mathrm{CP}}$ value is indicated in black above the bar. The build-up time of the solvent ${ }^{1} \mathrm{H}$ signals is given in parentheses. A $10 \%$ confidence interval on the measured enhancement is indicated.

results in the concentration range between 1 and $40 \mathrm{mM}$ in DMSO- $d_{6}: \mathrm{D}_{2} \mathrm{O}: \mathrm{H}_{2} \mathrm{O}(60: 30: 10 \mathrm{v} / \mathrm{v} / \mathrm{v})$. While there are no major differences in the polarization build-up times between the two classes (except between 1 and $3 \mathrm{mM}$ ), we observe a significantly higher $\varepsilon_{\mathrm{C} C P}$ for $\mathbf{1 0}$ than for $\mathbf{1 1}$ at all concentrations over $1 \mathrm{mM}$. The enhancements level off for concentrations equal to or greater than $20 \mathrm{mM}$. The combination of SE and CE DNP mechanisms can account for the observed trend of the enhancement as a function of the concentration, with the relative weight of intermolecular $\mathrm{CE}$ increasing at increased radical concentrations and possibly producing a larger difference in MAS DNP enhancements between 11 and 12. Both radicals exhibit the expected concentration dependence, analogous to that previously observed for dinitroxides. ${ }^{87}$ Finally, the different combination of DNP mechanisms could account for the factor of $\sim 2-3$ difference (e.g., 119/41 for $\mathbf{1 1}$ and 12 versus $250 / 23$ for 2 and 3) between monoradicals and biradicals in MAS DNP performance.

Are C-Radicals Useless? Despite a comparatively poorer enhancement for all of the investigated C-radicals $(3,6,8$, and 12), they may still be interesting candidates in applications performed under reducing conditions (in-cell DNP, ${ }^{2,88}$ for example). In AMUPol (1), the room-temperature dynamic process exchanging $\mathrm{O}$ - and $\mathrm{C}$-conformations will lead, in the presence of reducing agents, to the quick inactivation of the radical. ${ }^{65}$ The same process will be operational for both the Oand $\mathrm{C}$-conformers. However, due to the different degree of steric hindrance, the $\mathrm{C}$-conformer is inactivated on a longer time scale. Figure 3 shows the reduction kinetics, measured by

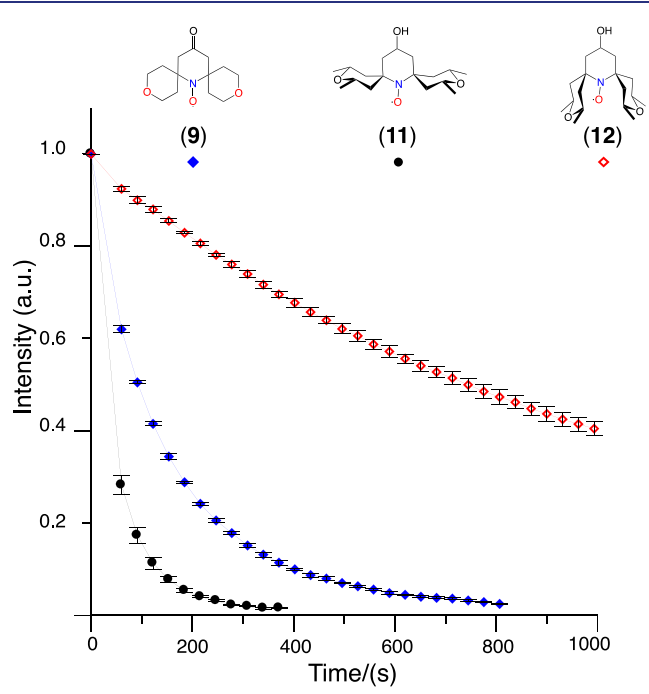

Figure 3. Reduction profiles measured through the intensity of EPR signals of $0.2 \mathrm{mM}$ nitroxides (9 in blue, 11 in black, and 12 in red) in $0.2 \mathrm{mM}$ ascorbic acid in $\mathrm{H}_{2} \mathrm{O}$ at $295 \mathrm{~K}$.

$\mathrm{EPR}$, for the monoradicals $\mathbf{9}, \mathbf{1 1}$, and $\mathbf{1 2}$ with $0.2 \mathrm{mM}$ ascorbic acid in $\mathrm{H}_{2} \mathrm{O}$ at $295 \mathrm{~K}$. The slower reduction for C-MbPyTol (12) is indicative of a better resistance to reducing environments. We ascribe this effect to different solvent accessibilities to the nitroxide regions, caused by different local conformations, as further supported below by ESEEM experiments and calculated solvent-accessible surface (Figure S33).

In addition to the interplay between different DNP mechanisms, the clear-cut difference in terms of MAS DNP enhancement between the $\mathrm{O}$ - and $\mathrm{C}$-classes shown in Figures 1 and 2 could be due to a number of further factors: (a) differences in electron relaxation times, (b) influence of local relaxation sinks, and (c) other factors induced by the structural difference between the conformers. Importantly, the relative difference in performance persists across different solvents and concentrations and is observed in both mono- and biradicals.

Saturation Factor. Previous investigations showed that MAS DNP enhancement is closely related to the electron spin relaxation properties of the radical, and the phenomenological 
saturation factor $\left(T_{1 \mathrm{e}} T_{2 \mathrm{e}}\right.$ or $\left.T_{\mathrm{IR}} T_{\mathrm{M}}\right)$ is used as a convenient metric, with higher saturation factors leading to larger MAS DNP enhancements. ${ }^{55,74}$ In the case of 2 and 3, pulsed EPR experiments at $94.1 \mathrm{GHz}$ were conducted at $3.2 \mathrm{mM}$ in DMSO- $d_{6}: \mathrm{D}_{2} \mathrm{O}: \mathrm{H}_{2} \mathrm{O}(60: 30: 10 \mathrm{v} / \mathrm{v} / \mathrm{v})$ and $16 \mathrm{mM}$ in TCE and $105 \mathrm{~K}$ in order to determine electron $T_{\mathrm{IR}}$ and $T_{\mathrm{M}}$ (SI section 10). The results are summarized in Table 1 . In

Table 1. Saturation Factors $\left(T_{\mathrm{IR}}, T_{\mathrm{M}}\right.$, and $\left.T_{\mathrm{IR}} T_{\mathrm{M}}\right)$ and MAS DNP Enhancements $\left(\varepsilon_{\mathrm{ON} / \mathrm{OFF}}\right)$ for $3.2 \mathrm{mM}$ solutions of 2 and 3 in DMSO- $d_{6}: \mathrm{D}_{2} \mathrm{O}: \mathrm{H}_{2} \mathrm{O}(60: 30: 10 \mathrm{v} / \mathrm{v} / \mathrm{v})(\mathrm{D} / \mathrm{w})$ and for $16 \mathrm{mM}$ solutions of 2 and 3 in 1,1,2,2-Tetrachloroethane (TCE) at $105 \mathrm{~K}$

\begin{tabular}{|c|c|c|c|c|c|c|c|c|}
\hline & \multicolumn{2}{|c|}{$T_{\mathrm{IR}}(\mu \mathrm{s})$} & \multicolumn{2}{c|}{$T_{\mathrm{M}}(\mathrm{ns})$} & \multicolumn{2}{c|}{$T_{\mathrm{IR}} T_{\mathrm{M}}\left(\mu \mathrm{s}^{2}\right)$} & \multicolumn{2}{c|}{$\varepsilon_{\mathrm{ON} / \text { OFF }}$} \\
\hline $\mathrm{R}$ & $\mathrm{D} / \mathrm{w}$ & $\mathrm{TCE}$ & $\mathrm{D} / \mathrm{w}$ & $\mathrm{TCE}$ & $\mathrm{D} / \mathrm{w}$ & $\mathrm{TCE}$ & $\mathrm{D} / \mathrm{w}$ & $\mathrm{TCE}$ \\
\hline $\mathbf{2}$ & 168 & 78 & 581 & 411 & 98 & 32 & 250 & 102 \\
\hline 3 & 116 & 70 & 862 & 864 & 100 & 81 & 23 & 14 \\
\hline
\end{tabular}

DMSO/water there is virtually no difference between the saturation factors of $\mathbf{2}$ and 3. In TCE, the saturation factor of C-MAMUPol (3) is a factor of 2 larger, which does not correlate with its much lower MAS DNP enhancement. This surprising result indicates that the electronic relaxation properties do not explain the difference in MAS DNP performance between $\mathrm{O}$ - and $\mathrm{C}$-conformers.

Role of $-\mathrm{CH}_{3}$ Groups. The electronic phase memory time, $T_{\mathrm{M}}$, in glassy frozen solutions at $100 \mathrm{~K}$ is largely driven by molecular motions and librations, ${ }^{89}$ and rotation of methyl groups is effective at inducing transverse electron relaxation. The efficiency of this process is a function of temperature and depends on the energy barrier for methyl rotation. ${ }^{89}$ The presence of methyl groups in the proximity of the unpaired electron therefore acts as an electronic relaxation sink and is thought to hamper MAS DNP performance. Methyl groups, which still undergo fast rotation at $100 \mathrm{~K}$, also act as nuclear relaxation sinks, and this is known to be detrimental for MAS DNP. ${ }^{79}$ Indeed, deuteration of the methyl locking groups in $\mathbf{1 0}$ results in a $\sim 10 \%$ greater enhancement as compared to $11\left(\varepsilon_{1 \mathrm{H}}\right.$ $=42 \pm 1$ for 10 versus $\varepsilon_{1 \mathrm{H}}=38 \pm 1$ for 11$)$ and $\sim 40 \%$ longer polarization build-up time $\left(T_{\mathrm{b}, \text { on }}=2.4 \mathrm{~s}\right.$ for 10 versus $T_{\mathrm{b}, \text { on }}=$ $1.7 \mathrm{~s}$ for 11) in TCE. It is also worth mentioning that, for nuclear spins, DNP-induced cross-relaxation in methyl groups is an interesting feature for protein and amino acids investigations ${ }^{90,91}$ and has been shown to have long-lived properties, in specific cases, at about $1 \mathrm{~K} .{ }^{92,93}$ Table 1 shows the electron relaxation data obtained for 2 and 3 under conditions identical to those used in a MAS DNP experiment. The $T_{M}$ of C-MAMUPol (3) is longer than that of $\mathrm{O}$ MAMUPol (2) in both DMSO/water and TCE, even though in the C-conformer the methyl groups are closer in space to the unpaired electron. The distribution of distances between the unpaired electron and the methyl group protons is shown in Figure $4 b$, extracted from the MD trajectories in SI section 9, and we find values between 4 and $5.5 \AA$ for 12 , whereas for 11 we find values between $\sim 4.5$ and $\sim 6.3 \AA$ (see also Figure S18 and Table S10).

This result shows that differences in the methyl-induced electron relaxation do not appear to be the limiting factor in determining the differences in DNP performance between the open and closed radicals. Additionally, a comparison between
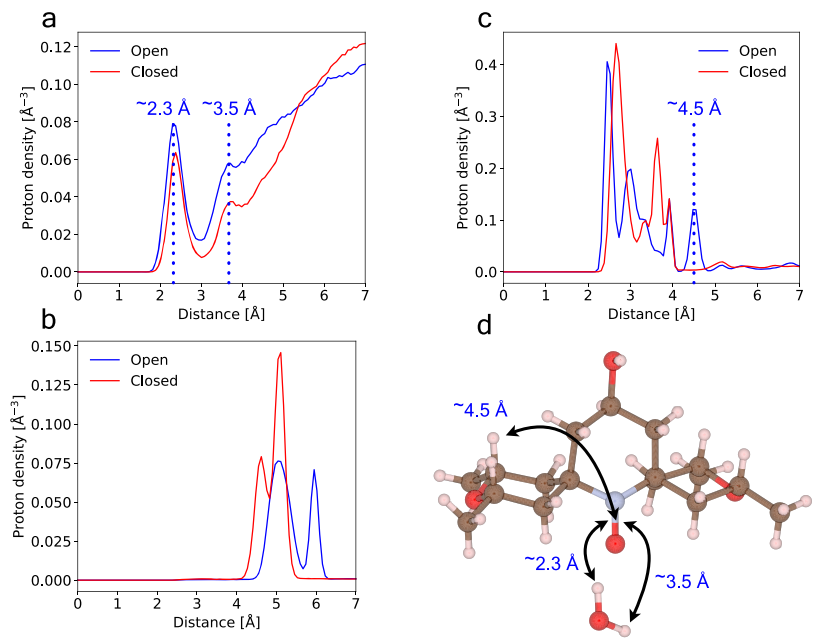

Figure 4. Proton densities for (a) solvent water protons, (b) methyl $\mathrm{CH}_{3}$, and (c) other radical protons in a sphere of $7 \AA$ from the $\mathrm{N}-\mathrm{O}$ radical from MD trajectories described in SI section 9. (d) Pictorial representation of the nuclei involved and distances to $\mathrm{N}-\mathrm{O}$, including the nearest water molecule (of the many taken into account), considering the structure of O-MbPyTol (11) as a example.

the MAS DNP enhancements of 13 and 14, where methyl groups have been replaced by bulkier phenyl substituents, again shows better performance for the $\mathrm{O} / \mathrm{C}$-conformer, despite a similar build-up time for proton polarization in TCE.

Correlation between Solvent Accessibility and MAS DNP Enhancement. We have hypothesized that the difference between the $\mathrm{O}$ - and $\mathrm{C}$-conformations may affect solvent accessibility around the nitroxide, thereby affecting the first few polarization transfer steps.

The structures of the $\mathrm{O}$ - and $\mathrm{C}$-isomers of the nitroxide were confirmed by X-ray crystal structure analysis (Figures S16S19). The accessibility around the $\mathrm{N}-\mathrm{O}$ bond has been estimated by calculating the solvent-accessible surface (SAS) for a water molecule using Jmol software ${ }^{94}$ (Figure S33). The major electron spin density of a TEMPO-like nitroxide locates on $\mathrm{N}-\mathrm{O}$ site with a nearly equal distribution on the nitrogen and oxygen atoms. Values of 20.60 and $0.45 \AA^{2}$ for the oxygen and nitrogen atoms, respectively, for O-MbPyTol (11) and of 9.69 and $0.06 \AA^{2}$ for the oxygen and nitrogen atoms, respectively, for $\mathrm{C}-\mathrm{MbPyTol}$ (12) were obtained, illustrating the significant difference in solvent accessibility.

Experimentally, we have probed solvent accessibility using pulsed EPR. ESEEM has been demonstrated to provide reliable information on water accessibility in large transmembrane proteins ${ }^{82}$ and water penetration in micelles by quantification of hyperfine couplings to deuterium nuclei in deuterated water molecules. It allows the estimation of the number of nuclear spins in the vicinity of the electron spin on a length scale between 3 and $6 \AA$. The ESEEM effect arises from partially allowed transitions occurring with the simultaneous change of the electron and nuclear magnetic spin quantum numbers.

The three-pulse ESEEM consists of the following sequence of pulses: $\pi / 2-\tau-\pi / 2-T-\pi / 2-\tau$-echo as described in the EPR Spectroscopy section above. The intensity of the echo signal is modulated by the hyperfine interaction between the electron spin and vicinal ${ }^{2} \mathrm{H}$ nuclei during the variable delay $T$ resulting in an oscillating decay as shown in Figure 5. In the three-pulse ESEEM experiment, the modulation depth, $K$, is defined as the 

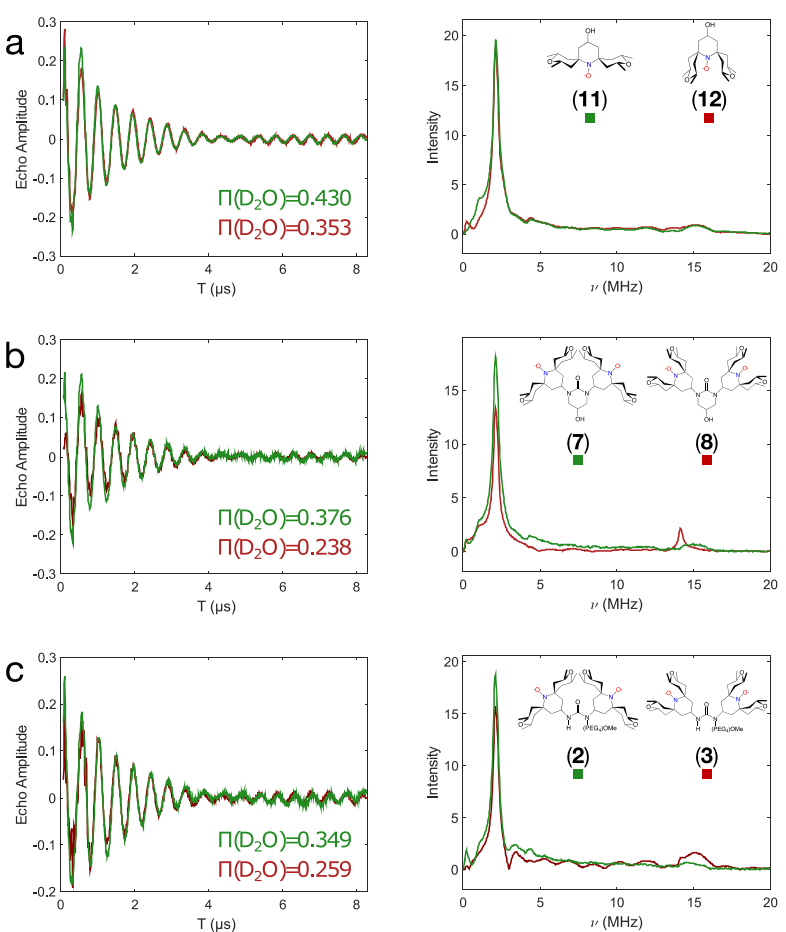

Figure 5. Three-pulse ESEEM time-domain data and the corresponding magnitude spectra: (a) for $\mathbf{1 1}$ and 12 in DMSO- $d_{6}: \mathrm{D}_{2} \mathrm{O}: \mathrm{H}_{2} \mathrm{O}$ $(60: 30: 10 \mathrm{v} / \mathrm{v} / \mathrm{v}) ;(\mathrm{b})$ for 7 and 8 in DMSO- $d_{6}: \mathrm{D}_{2} \mathrm{O}: \mathrm{H}_{2} \mathrm{O}(60: 30: 10$ $\mathrm{v} / \mathrm{v} / \mathrm{v})$; and (c) for 2 and 3 in glycerol- $d_{8}: \mathrm{D}_{2} \mathrm{O}: \mathrm{H}_{2} \mathrm{O}(60: 30: 10 \mathrm{v} / \mathrm{v} / \mathrm{v})$ at $50 \mathrm{~K}$ and $200 \mu \mathrm{M}$. The solvent accessibility parameter $\Pi\left(\mathrm{D}_{2} \mathrm{O}\right)$, defined in eq SI-6, is always larger for the O-class: $\Pi^{\mathrm{O}-}\left(\mathrm{D}_{2} \mathrm{O}\right)>$ $\Pi^{\mathrm{C}-}\left(\mathrm{D}_{2} \mathrm{O}\right)$. We note that in the case of $\mathrm{C}-\mathrm{PyPolC} \mathrm{C}_{6} \mathrm{OH}(8)$ the proton modulation is not completely suppressed, leading to a small peak at the ${ }^{1} \mathrm{H}$ Larmor frequency at ca. $15 \mathrm{MHz}$.

peak-to-peak distance between the first maximum and the first minimum in the deuterium modulation. The ${ }^{2} \mathrm{H}$ modulation profiles for the investigated mono- and biradicals are shown in Figure 5.

Experimentally, in order to minimize the influence of ${ }^{1} \mathrm{H}$ on the ${ }^{2} \mathrm{H}$ modulations, the measurements were performed with $\tau$ $=344 \mathrm{~ns}$ which corresponds to the $j=5$ blind spot of proton modulation: $\nu_{\mathrm{H}} \tau=5$, where $\nu_{\mathrm{H}}$ represents the ${ }^{1} \mathrm{H}$ Larmor frequency at $\mathrm{X}$ band. It was previously demonstrated that the choice of $j=5$ leads to optimal suppression of the hydrogenbonded deuterons and, as a result, to more stable fits of the non-hydrogen-bonded ESEEM modulation. ${ }^{82}$ Fourier transformation of the normalized nuclear modulation function and computation of the absolute value provide the magnitude spectrum (see Figure 5). The intensity $I\left(\nu_{\mathrm{D}}\right)$ of the ${ }^{2} \mathrm{H}$ at the frequency $\nu_{\mathrm{D}}$ is proportional to the modulation depth $K$, as discussed in ref 82 . The ESEEM experiments return the highest $I\left(\nu_{\mathrm{D}}\right)$ of the ${ }^{2} \mathrm{H}$ signal for the O-class of biradical systems (Figure 5).

The higher intensity $\mathrm{I}\left(\nu_{\mathrm{D}}\right)$ for the O-class can be interpreted as a greater solvent accessibility to the nitroxide region for this class of PAs. The solvent accessibility parameter $\Pi$, defined in ref 82 , is $18 \%$ greater for O-MbPyTol (11), 37\% for O$\mathrm{PyPolC}_{6} \mathrm{OH}$ (7), and 26\% for O-MAMUPol (2) as compared to the corresponding C-class analogues (12, 8, and 3, respectively) and positively correlates with the MAS DNP enhancements reported in Figure 1.

In further support of modified solvent accessibility, Figure 4 shows the radial ${ }^{1} \mathrm{H}$ density in a sphere of $7 \AA$ from middle of the NO bond calculated from 10001 snapshots from the MD trajectories for $\mathbf{2}$ and 3 (see section SI 9.2). The ${ }^{1} \mathrm{H}$ densities have been divided into three groups: water protons (Figure $4 \mathrm{a}$ ), methyl $\mathrm{CH}_{3}$ protons (Figure $4 \mathrm{~b}$ ), and other radical protons (Figure 4c). Figure S35 shows these distributions superimposed in the same vertical scale, as well as for $\mathbf{7}$ and $\mathbf{8}$. Note that in the DNP samples, the $\mathrm{H}_{2} \mathrm{O}$ is $75 \%$ deuterated, so the water proton density should be divided by 4 . Note also that the $\mathrm{MD}$ trajectories were calculated in pure $\mathrm{H}_{2} \mathrm{O}$, which does not therefore take into account the potential perturbations due to the DMSO present in the DNP formulation.

As shown in Figure 4, the water protons have a higher density for O-MAMUPol (2) as compared to the closed analogue, which is in good agreement with the ESEEM measurements discussed above. The two local maxima at $\sim 2.3$ and $\sim 3.5 \AA$ are due to the first directly coordinated water molecule (see Figure $4 \mathrm{~d}$ ). Table S5 gives the number of the different types of protons contained in 5, 6, and $7 \AA$ radii around the nitroxide. We note also that the $\mathrm{CH}_{3}$ protons are not only closer to the NO in the closed forms, as discussed previously above, but also have a region of higher density. In addition, in O-MAMUPol (2) there is significant radical proton density reaching out to longer distances (around $\sim 4.5$ $\AA$ ) than in the closed isomer. All these differences can lead to different polarization transfer pathways between the $\mathrm{O}$ - and $\mathrm{C}$ radicals into the bulk. For example the lower density of $\mathrm{CH}_{3}$ protons as compared to the solvent and radical protons could potentially modify the polarization dynamics in the O-isomers across the spin diffusion barrier normally present in DNP experiments. $^{94}$

\section{CONCLUSIONS}

We have introduced a set of 13 new nitroxide mono- and biradicals as PAs for MAS DNP at $9.4 \mathrm{~T}$ and $100 \mathrm{~K}$. They have been grouped into $\mathrm{O}$ - and $\mathrm{C}$-classes depending on the conformation of the tetrahydropyran rings in the regions around the $\mathrm{NO}^{\bullet}$ moieties (Scheme 2 ). We observe a significant difference in the MAS DNP performance for the two classes, with the $\mathrm{O}$ - class yielding an order of magnitude better result than the corresponding $\mathrm{C}$-analogues for bis-nitroxides. The strikingly higher enhancement for the O-class is preserved across different DNP media. We have shown that these results cannot be exclusively rationalized in terms of solvent-induced variations in local conformation, different saturation factors or methyl-induced relaxation. The limited DNP enhancement for the C-biradicals can, in some cases, be partially due to stronger magnetic interactions (large values of $|J|)$. However, it cannot account for the difference between $\mathrm{C}$ - and O-monoradicals, where no exchange coupling is present. SAS simulations and the ESEEM experiment confirm a higher local solvent accessibility in the O-class radicals. This positively correlates with the MAS DNP results. Changes in the local concentration of the different types of protons in the vicinity of the unpaired electron could affect the first steps of the spin diffusion process, leading to the observed changes in the MAS DNP bulk solvent enhancement.

This study highlights the, so far overlooked, crucial importance of local conformational changes in the determination of both magnetic and bulk solvent accessibility properties, introducing a new design principle for the synthesis of efficient radicals tailored for high field MAS DNP. HydrOPol (5) gives a proton enhancement at $9.4 \mathrm{~T}$ of 330, which is about $80 \%$ higher than AMUPol (1) under these 
conditions of field, concentration and solvent (DMSO$\left.d_{6}: \mathrm{D}_{2} \mathrm{O}: \mathrm{H}_{2} \mathrm{O}(60: 30: 10 \mathrm{v} / \mathrm{v} / \mathrm{v})\right)$. In addition, the monoradical O-MbPyTol (11) yields a proton enhancement of 119 at $9.4 \mathrm{~T}$ in DMSO/water which is, to the best of our knowledge, the highest MAS DNP proton enhancement at $9.4 \mathrm{~T}$ and $100 \mathrm{~K}$ so far reported for a mononitroxide. The relevance of the principle introduced here has already very recently been supported by the introduction of $\mathrm{M}$-TinyPol radical (the $\mathrm{O}$ derivative of TinyPol), designed for high fields, and which also yielded the highest reported proton enhancements so far for MAS DNP at $100 \mathrm{~K}$ at 18.8 and $21.15 \mathrm{~T}$ (90 and 32 respectively, at $10 \mathrm{mM}$ in glycerol- $d_{8}: \mathrm{D}_{2} \mathrm{O}: \mathrm{H}_{2} \mathrm{O}(60: 30: 10 \mathrm{v} / \mathrm{v} /$ v)). ${ }^{61}$

\section{ASSOCIATED CONTENT}

\section{SI Supporting Information}

The Supporting Information is available free of charge at https://pubs.acs.org/doi/10.1021/jacs.0c04911.

Synthetic details, experimental protocols, and supporting data, including Figures S1-S41 and Tables S1-S12 (PDF)

\section{AUTHOR INFORMATION}

\section{Corresponding Authors}

Lyndon Emsley - Institut des Sciences et Ingénierie Chimiques, Ecole Polytechnique Féderale de Lausanne (EPFL), CH-1015 Lausanne, Switzerland; 이이.org/0000-0003-1360-2572; Email: lyndon.emsley@epfl.ch

Olivier Ouari - Institut des Sciences et Ingénierie Chimiques, Ecole Polytechnique Féderale de Lausanne (EPFL), CH-1015 Lausanne, Switzerland; 이이. orcidorg/0000-0003-4320-4313; Email: olivier.ouari@univ-amu.fr

\section{Authors}

Gabriele Stevanato - Institut des Sciences et Ingénierie Chimiques, Ecole Polytechnique Féderale de Lausanne (EPFL), CH-1015 Lausanne, Switzerland; (1) orcid.org/0000-00030020-1286

Gilles Casano - Aix Marseille Universite, CNRS, ICR UMR 7273, 13013 Marseille, France; ○ orcid.org/0000-00016642-4808

Dominik J. Kubicki - Institut des Sciences et Ingénierie Chimiques, Ecole Polytechnique Féderale de Lausanne (EPFL), CH-1015 Lausanne, Switzerland; 이이이.org/0000-00029231-6779

Yu Rao - Institut des Sciences et Ingénierie Chimiques, Ecole Polytechnique Féderale de Lausanne (EPFL), CH-1015 Lausanne, Switzerland; orcid.org/0000-0002-9787-5596

Laura Esteban Hofer - Department of Chemistry, Laboratory of Physical Chemistry, ETH Zurich, 8093 Zurich, Switzerland; (1) orcid.org/0000-0002-5793-116X

Georges Menzildjian - Centre de RMN à Très Hauts Champs, Université de Lyon (CNRS/ENS de Lyon/UCB-Lyon 1), 69100 Villeurbanne, France; (1) orcid.org/0000-0001-62850447

Hakim Karoui - Aix Marseille Universite, CNRS, ICR UMR 7273, 13013 Marseille, France; 이이.org/0000-00015423-2358

Didier Siri - Aix Marseille Université, CNRS, ICR UMR 7273, 13013 Marseille, France
Manuel Cordova - Institut des Sciences et Ingénierie Chimiques, Ecole Polytechnique Féderale de Lausanne (EPFL), CH-1015 Lausanne, Switzerland; 이이이.org/0000-0002-8722-6541

Maxim Yulikov - Department of Chemistry, Laboratory of Physical Chemistry, ETH Zurich, 8093 Zurich, Switzerland; (1) orcid.org/0000-0003-3275-0714

Gunnar Jeschke - Department of Chemistry, Laboratory of Physical Chemistry, ETH Zurich, 8093 Zurich, Switzerland; (1) orcid.org/0000-0001-6853-8585

Moreno Lelli - Magnetic Resonance Center (CERM/ CIRMMP) and Department of Chemistry "Ugo Schiff", University of Florence, 50019 Sesto Fiorentino, Florence, Italy; (1) orcid.org/0000-0002-7042-2335

Anne Lesage - Centre de RMN à Très Hauts Champs, Université de Lyon (CNRS/ENS de Lyon/UCB-Lyon 1), 69100 Villeurbanne, France; (1) orcid.org/0000-0003-19582840

Complete contact information is available at: https://pubs.acs.org/10.1021/jacs.0c04911

\section{Author Contributions}

${ }^{\mathrm{II}}$ G.S. and G.C. contributed equally.

\section{Notes}

The authors declare no competing financial interest. The raw data reported herein are available at https://zenodo. org/record/4030683\#.X2EFMxMzYq9.

\section{ACKNOWLEDGMENTS}

We acknowledge Dr. Brennan J. Walder and Dr. David Gajan for enlightening discussions and experimental help, and financial support from Swiss National Science Foundation Grant No. 200020_178860. Financial support from ANR-15CE29-0022-01 is acknowledged. M.L. thanks the CR Firenze Foundation and the Instruct-ERIC JRA (APPID 820) project for funding. G.S. acknowledges Marie-Skłodowska-Curie Grant 796904.

\section{REFERENCES}

(1) Rossini, A. J.; Zagdoun, A.; Lelli, M.; Lesage, A.; Coperet, C.; Emsley, L. Dynamic Nuclear Polarization Surface Enhanced NMR Spectroscopy. Acc. Chem. Res. 2013, 46 (9), 1942-1951.

(2) Thankamony, A. S. L.; Wittmann, J. J.; Kaushik, M.; Corzilius, B. Dynamic nuclear polarization for sensitivity enhancement in modern solid-state NMR. Prog. Nucl. Magn. Reson. Spectrosc. 2017, 102, 120195.

(3) Ni, Q. Z.; Daviso, E.; Can, T. V.; Markhasin, E.; Jawla, S. K.; Swager, T. M.; Temkin, R. J.; Herzfeld, J.; Griffin, R. G. High Frequency Dynamic Nuclear Polarization. Acc. Chem. Res. 2013, 46 (9), 1933-1941.

(4) Chaudhari, S. R.; Wisser, D.; Pinon, A. C.; Berruyer, P.; Gajan, D.; Tordo, P.; Ouari, O.; Reiter, C.; Engelke, F.; Coperet, C.; Lelli, M.; Lesage, A.; Emsley, L. Dynamic Nuclear Polarization Efficiency Increased by Very Fast Magic Angle Spinning. J. Am. Chem. Soc. 2017, 139 (31), 10609-10612.

(5) Lesage, A.; Lelli, M.; Gajan, D.; Caporini, M. A.; Vitzthum, V.; Mieville, P.; Alauzun, J.; Roussey, A.; Thieuleux, C.; Mehdi, A.; Bodenhausen, G.; Coperet, C.; Emsley, L. Surface Enhanced NMR Spectroscopy by Dynamic Nuclear Polarization. J. Am. Chem. Soc. 2010, 132 (44), 15459-15461.

(6) Blanc, F.; Chong, S. Y.; McDonald, T. O.; Adams, D. J.; Pawsey, S.; Caporini, M. A.; Cooper, A. I. Dynamic Nuclear Polarization NMR Spectroscopy Allows High-Throughput Characterization of Microporous Organic Polymers. J. Am. Chem. Soc. 2013, 135 (41), 1529015293. 
(7) Ouari, O.; Phan, T.; Ziarelli, F.; Casano, G.; Aussenac, F.; Thureau, P.; Gigmes, D.; Tordo, P.; Viel, S. Improved Structural Elucidation of Synthetic Polymers by Dynamic Nuclear Polarization Solid-State NMR Spectroscopy. ACS Macro Lett. 2013, 2 (8), 715719.

(8) Brownbill, N. J.; Sprick, R. S.; Bonillo, B.; Pawsey, S.; Aussenac, F.; Fielding, A. J.; Cooper, A. I.; Blanc, F. Structural Elucidation of Amorphous Photocatalytic Polymers from Dynamic Nuclear Polarization Enhanced Solid State NMR. Macromolecules 2018, 51 (8), 3088-3096.

(9) Chaudhari, S. R.; Griffin, J. M.; Broch, K.; Lesage, A.; Lemaur, V.; Dudenko, D.; Olivier, Y.; Sirringhaus, H.; Emsley, L.; Grey, C. P. Donor-acceptor stacking arrangements in bulk and thin-film highmobility conjugated polymers characterized using molecular modelling and MAS and surface-enhanced solid-state NMR spectroscopy. Chem. Sci. 2017, 8 (4), 3126-3136.

(10) Tanaka, S.; Liao, W. C.; Ogawa, A.; Sato, K.; Coperet, C. DNP NMR spectroscopy of cross-linked organic polymers: rational guidelines towards optimal sample preparation. Phys. Chem. Chem. Phys. 2020, 22 (6), 3184-3190.

(11) Sangodkar, R. P.; Smith, B. J.; Gajan, D.; Rossini, A. J.; Roberts, L. R.; Funkhouser, G. P.; Lesage, A.; Emsley, L.; Chmelka, B. F. Influences of Dilute Organic Adsorbates on the Hydration of LowSurface-Area Silicates. J. Am. Chem. Soc. 2015, 137, 8096-8112.

(12) Lelli, M.; Gajan, D.; Lesage, A.; Caporini, M. A.; Vitzthum, V.; Mieville, P.; Heroguel, F.; Rascon, F.; Roussey, A.; Thieuleux, C.; Boualleg, M.; Veyre, L.; Bodenhausen, G.; Coperet, C.; Emsley, L. Fast Characterization of Functionalized Silica Materials by Silicon-29. J. Am. Chem. Soc. 2011, 133, 2104-2107.

(13) Lafon, O.; Rosay, M.; Aussenac, F.; Lu, X. Y.; Trebosc, J.; Cristini, O.; Kinowski, C.; Touati, N.; Vezin, H.; Amoureux, J. P. Beyond the Silica Surface by Direct Silicon-29 Dynamic Nuclear Polarization. Angew. Chem., Int. Ed. 2011, 50 (36), 8367-8370.

(14) Gruning, W. R.; Rossini, A. J.; Zagdoun, A.; Gajan, D.; Lesage, A.; Emsley, L.; Coperet, C. Molecular-level characterization of the structure and the surface chemistry of periodic mesoporous organosilicates using DNP-surface enhanced NMR spectroscopy. Phys. Chem. Chem. Phys. 2013, 15 (32), 13270-13274.

(15) Lafon, O.; Thankamony, A. S. L.; Kobayashi, T.; Carnevale, D.; Vitzthum, V.; Slowing, I. I.; Kandel, K.; Vezin, H.; Amoureux, J. P.; Bodenhausen, G.; Pruski, M. Mesoporous Silica Nanoparticles Loaded with Surfactant: Low Temperature Magic Angle Spinning C-13 and Si-29 NMR Enhanced by Dynamic Nuclear Polarization. J. Phys. Chem. C 2013, 117 (3), 1375-1382.

(16) Rankin, A. G. M.; Webb, P. B.; Dawson, D. M.; Viger-Gravel, J.; Walder, B. J.; Emsley, L.; Ashbrook, S. E. Determining the Surface Structure of Silicated Alumina Catalysts via Isotopic Enrichment and Dynamic Nuclear Polarization Surface-Enhanced NMR Spectroscopy. J. Phys. Chem. C 2017, 121 (41), 22977-22984.

(17) Akbey, U.; Altin, B.; Linden, A.; Ozcelik, S.; Gradzielski, M.; Oschkinat, H. Dynamic nuclear polarization of spherical nanoparticles. Phys. Chem. Chem. Phys. 2013, 15 (47), 20706-20716.

(18) Protesescu, L.; Rossini, A. J.; Kriegner, D.; Valla, M.; de Kergommeaux, A.; Walter, M.; Kravchyk, K. V.; Nachtegaal, M.; Stangl, J.; Malaman, B.; Reiss, P.; Lesage, A.; Emsley, L.; Coperet, C.; Kovalenko, M. V. Unraveling the Core-Shell Structure of LigandCapped $\mathrm{Sn} / \mathrm{SnOx}$ Nanoparticles by Surface-Enhanced Nuclear Magnetic Resonance, Mossbauer, and X-ray Absorption Spectroscopies. ACS Nano 2014, 8 (3), 2639-2648.

(19) Hanrahan, M. P.; Chen, Y. H.; Blome-Fernandez, R.; Stein, J. L.; Pach, G. F.; Adamson, M. A. S.; Neale, N. R.; Cossairt, B. M.; Vela, J.; Rossini, A. J. Probing the Surface Structure of Semiconductor Nanoparticles by DNP SENS with Dielectric Support Materials. J. Am. Chem. Soc. 2019, 141 (39), 15532-15546.

(20) Rossini, A. J.; Widdifield, C. M.; Zagdoun, A.; Lelli, M.; Schwarzwalder, M.; Coperet, C.; Lesage, A.; Emsley, L. Dynamic Nuclear Polarization Enhanced NMR Spectroscopy for Pharmaceutical Formulations. J. Am. Chem. Soc. 2014, 136 (6), 2324-2334.
(21) Rossini, A. J.; Zagdoun, A.; Hegner, F.; Schwarzwalder, M.; Gajan, D.; Coperet, C.; Lesage, A.; Emsley, L. Dynamic Nuclear Polarization NMR Spectroscopy of Microcrystalline Solids. J. Am. Chem. Soc. 2012, 134 (40), 16899-16908.

(22) Pinon, A. C.; Rossini, A. J.; Widdifield, C. M.; Gajan, D.; Emsley, L. Polymorphs of Theophylline Characterized by DNP Enhanced Solid-State NMR. Mol. Pharmaceutics 2015, 12 (11), 4146-4153.

(23) Pinon, A. C.; Schlagnitweit, J.; Berruyer, P.; Rossini, A. J.; Lelli, M.; Socie, E.; Tang, M. X.; Pham, T.; Lesage, A.; Schantz, S.; Emsley, L. Measuring Nano- to Microstructures from Relayed Dynamic Nuclear Polarization NMR. J. Phys. Chem. C 2017, 121 (29), 1599316005 .

(24) Wolf, P.; Valla, M.; Rossini, A. J.; Comas-Vives, A.; NunezZarur, F.; Malaman, B.; Lesage, A.; Emsley, L.; Coperet, C.; Hermans, I. NMR Signatures of the Active Sites in Sn-beta Zeolite. Angew. Chem., Int. Ed. 2014, 53 (38), 10179-10183.

(25) Wolf, P.; Liao, W. C.; Ong, T. C.; Valla, M.; Harris, J. W.; Gounder, R.; van der Graaff, W. N. P.; Pidko, E. A.; Hensen, E. J. M.; Ferrini, P.; Dijkmans, J.; Sels, B.; Hermans, I.; Coperet, C. Identifying Sn Site Heterogeneities Prevalent Among Sn-Beta Zeolites. Helv. Chim. Acta 2016, 99 (12), 916-927.

(26) Perras, F. A.; Wang, Z. R.; Naik, P.; Slowing, I. I.; Pruski, M. Natural Abundance O-17 DNP NMR Provides Precise O-H Distances and Insights into the Bronsted Acidity of Heterogeneous Catalysts. Angew. Chem., Int. Ed. 2017, 56 (31), 9165-9169.

(27) Perras, F. A.; Wang, Z. C.; Kobayashi, T.; Baiker, A.; Huang, J.; Pruski, M. Shedding light on the atomic-scale structure of amorphous silica-alumina and its Bronsted acid sites. Phys. Chem. Chem. Phys. 2019, 21 (35), 19529-19537.

(28) Vitzthum, V.; Mieville, P.; Carnevale, D.; Caporini, M. A.; Gajan, D.; Coperet, C.; Lelli, M.; Zagdoun, A.; Rossini, A. J.; Lesage, A.; Emsley, L.; Bodenhausen, G. Dynamic nuclear polarization of quadrupolar nuclei using cross polarization from protons: surfaceenhanced aluminium-27 NMR. Chem. Commun. 2012, 48 (14), $1988-1990$.

(29) Kobayashi, T.; Pruski, M. Spatial Distribution of Silica-Bound Catalytic Organic Functional Groups Can. Now Be Revealed by Conventional and DNP-Enhanced Solid-State NMR Methods. ACS Catal. 2019, 9 (8), 7238-7249.

(30) Perras, F. A.; Boteju, K. C.; Slowing, I. I.; Sadow, A. D.; Pruski, M. Direct O-17 dynamic nuclear polarization of single-site heterogeneous catalysts. Chem. Commun. 2018, 54 (28), 3472-3475.

(31) Berruyer, P.; Lelli, M.; Conley, M. P.; Silverio, D. L.; Widdifield, C. M.; Siddiqi, G.; Gajan, D.; Lesage, A.; Coperet, C.; Emsley, L. Three-Dimensional Structure Determination of Surface Sites. J. Am. Chem. Soc. 2017, 139 (2), 849-855.

(32) Moroz, I. B.; Larmier, K.; Liao, W. C.; Coperet, C. Discerning gamma-Alumina Surface Sites with Nitrogen-15 Dynamic Nuclear Polarization Surface Enhanced NMR Spectroscopy of Adsorbed Pyridine. J. Phys. Chem. C 2018, 122 (20), 10871-10882.

(33) Moroz, I. B.; Lund, A.; Kaushik, M.; Severy, L.; Gajan, D.; Fedorov, A.; Lesage, A.; Coperet, C. Specific Localization of Aluminum Sites Favors Ethene-to-Propene Conversion on (Al)MCM-41-Supported Ni(II) Single Sites. ACS Catal. 2019, 9 (8), $7476-7485$.

(34) Jaudzems, K.; Polenova, T.; Pintacuda, G.; Oschkinat, H.; Lesage, A. DNP NMR of biomolecular assemblies. J. Struct. Biol. 2019, 206 (1), 90-98.

(35) Ardenkjaer-Larsen, J. H.; Boebinger, G. S.; Comment, A.; Duckett, S.; Edison, A. S.; Engelke, F.; Griesinger, C.; Griffin, R. G.; Hilty, C.; Maeda, H.; Parigi, G.; Prisner, T.; Ravera, E.; van Bentum, J.; Vega, S.; Webb, A.; Luchinat, C.; Schwalbe, H.; Frydman, L. Facing and Overcoming Sensitivity Challenges in Biomolecular NMR Spectroscopy. Angew. Chem., Int. Ed. 2015, 54 (32), 9162-9185.

(36) van der Cruijsen, E. A. W.; Koers, E. J.; Sauvee, C.; Hulse, R. E.; Weingarth, M.; Ouari, O.; Perozo, E.; Tordo, P.; Baldus, M. Biomolecular DNP-Supported NMR Spectroscopy using SiteDirected Spin Labeling. Chem. - Eur. J. 2015, 21 (37), 12971-12977. 
(37) Sergeyev, I. V.; Itin, B.; Rogawski, R.; Day, L. A.; McDermott, A. E. Efficient assignment and NMR analysis of an intact virus using sequential side-chain correlations and DNP sensitization. Proc. Natl. Acad. Sci. U. S. A. 2017, 114 (20), 5171-5176.

(38) Jaudzems, K.; Bertarello, A.; Chaudhari, S. R.; Pica, A.; Cala-De Paepe, D.; Barbet-Massin, E.; Pell, A. J.; Akopjana, I.; Kotelovica, S.; Gajan, D.; Ouari, O.; Tars, K.; Pintacuda, G.; Lesage, A. Dynamic Nuclear Polarization-Enhanced Biomolecular NMR Spectroscopy at High Magnetic Field with Fast Magic-Angle Spinning. Angew. Chem., Int. Ed. 2018, 57 (25), 7458-7462.

(39) Smith, A. N.; Caporini, M. A.; Fanucci, G. E.; Long, J. R. A Method for Dynamic Nuclear Polarization Enhancement of Membrane Proteins. Angew. Chem., Int. Ed. 2015, 54 (5), 1542-1546.

(40) Smith, A. N.; Twahir, U. T.; Dubroca, T.; Fanucci, G. E.; Long, J. R. Molecular Rationale for Improved Dynamic Nuclear Polarization of Biomembranes. J. Phys. Chem. B 2016, 120 (32), 7880-7888.

(41) Smith, A. N.; Long, J. R. Dynamic Nuclear Polarization as an Enabling Technology for Solid State Nuclear Magnetic Resonance Spectroscopy. Anal. Chem. 2016, 88 (1), 122-132.

(42) Liu, G. Q.; Liou, S. H.; Enkin, N.; Tkach, I.; Bennati, M. Photoinduced radical polarization and liquid-state dynamic nuclear polarization using fullerene nitroxide derivatives. Phys. Chem. Chem. Phys. 2017, 19 (47), 31823-31829.

(43) Liu, G. Q.; Levien, M.; Karschin, N.; Parigi, G.; Luchinat, C.; Bennati, M. One-thousand-fold enhancement of high field liquid nuclear magnetic resonance signals at room temperature. Nat. Chem. 2017, 9 (7), 676-680.

(44) Jannin, S.; Dumez, J. N.; Giraudeau, P.; Kurzbach, D. Application and methodology of dissolution dynamic nuclear polarization in physical, chemical and biological contexts. J. Magn. Reson. 2019, 305, 41-50.

(45) Jannin, S.; Bornet, A.; Melzi, R.; Bodenhausen, G. High field dynamic nuclear polarization at $6.7 \mathrm{~T}$ : Carbon-13 polarization above $70 \%$ within 20 min. Chem. Phys. Lett. 2012, 549, 99-102.

(46) Ardenkjaer-Larsen, J. H.; Fridlund, B.; Gram, A.; Hansson, G.; Hansson, L.; Lerche, M. H.; Servin, R.; Thaning, M.; Golman, K. Increase in signal-to-noise ratio of $>10,000$ times in liquid-state NMR. Proc. Natl. Acad. Sci. U. S. A. 2003, 100 (18), 10158-10163.

(47) Wenckebach, W. T. Essentials of Dynamic Nuclear Polarisation; Spindrift Publications, 2016.

(48) Overhauser, A. W. Polarization of Nuclei in Metals. Phys. Rev. 1953, 92 (2), 411-415.

(49) Thurber, K. R.; Tycko, R. Theory for cross effect dynamic nuclear polarization under magic-angle spinning in solid state nuclear magnetic resonance: The importance of level crossings. J. Chem. Phys. 2012, 137 (8), 084508.

(50) Gennaro, A.; Karabanov, A.; Potapov, A.; Kockenberger, W. Heteronuclear DNP of (1)H and (19)F nuclei using BDPA as a polarizing agent. Phys. Chem. Chem. Phys. 2020, 22, 7803-7816.

(51) Equbal, A.; Li, Y.; Tabassum, T.; Han, S. Crossover from Solid Effect to Thermal Mixing (1)H Dynamic Nuclear Polarization in Trityl-OX063. J. Phys. Chem. Lett. 2020, 11 (9), 3718-3723.

(52) Casano, G.; Karoui, H.; Ouari, O. Polarizing Agents: Evolution and Outlook in Free Radical Development for DNP. Emagres 2018, 7 (4), 195-207.

(53) Wisser, D.; Karthikeyan, G.; Lund, A.; Casano, G.; Karoui, H.; Yulikov, M.; Menzildjian, G.; Pinon, A. C.; Purea, A.; Engelke, F.; Chaudhari, S. R.; Kubicki, D.; Rossini, A. J.; Moroz, I. B.; Gajan, D.; Coperet, C.; Jeschke, G.; Lelli, M.; Emsley, L.; Lesage, A.; Ouari, O. BDPA-Nitroxide Biradicals Tailored for Efficient Dynamic Nuclear Polarization Enhanced Solid-State NMR at Magnetic Fields up to 21.1 T. J. Am. Chem. Soc. 2018, 140 (41), 13340-13349.

(54) Sauvee, C.; Casano, G.; Abel, S.; Rockenbauer, A.; Akhmetzyanov, D.; Karoui, H.; Siri, D.; Aussenac, F.; Maas, W.; Weber, R. T.; Prisner, T.; Rosay, M.; Tordo, P.; Ouari, O. Tailoring of Polarizing Agents in the bTurea Series for Cross-Effect Dynamic Nuclear Polarization in Aqueous Media. Chem. - Eur. J. 2016, 22 (16), $5598-5606$.
(55) Kubicki, D. J.; Casano, G.; Schwarzwalder, M.; Abel, S.; Sauvee, C.; Ganesan, K.; Yulikov, M.; Rossini, A. J.; Jeschke, G.; Coperet, C.; Lesage, A.; Tordo, P.; Ouari, O.; Emsley, L. Rational design of dinitroxide biradicals for efficient cross-effect dynamic nuclear polarization. Chem. Sci. 2016, 7 (1), 550-558.

(56) Song, C. S.; Hu, K. N.; Joo, C. G.; Swager, T. M.; Griffin, R. G. TOTAPOL: A biradical polarizing agent for dynamic nuclear polarization experiments in aqueous media. J. Am. Chem. Soc. 2006, 128 (35), 11385-11390.

(57) Sauvée, C.; Rosay, M.; Casano, G.; Aussenac, F.; Weber, R. T.; Ouari, O.; Tordo, P. Highly efficient, water-soluble polarizing agents for dynamic nuclear polarization at high frequency. Angew. Chem., Int. Ed. 2013, 52, 10858-10861.

(58) Zagdoun, A.; Casano, G.; Ouari, O.; Schwarzwalder, M.; Rossini, A. J.; Aussenac, F.; Yulikov, M.; Jeschke, G.; Coperet, C.; Lesage, A.; Tordo, P.; Emsley, L. Large Molecular Weight Nitroxide Biradicals Providing Efficient Dynamic Nuclear Polarization at Temperatures up to 200 K. J. Am. Chem. Soc. 2013, 135 (34), 12790-12797.

(59) Mentink-Vigier, F.; Marin-Montesinos, I.; Jagtap, A. P.; Halbritter, T.; van Tol, J.; Hediger, S.; Lee, D.; Sigurdsson, S. T.; De Paepe, G. Computationally Assisted Design of Polarizing Agents for Dynamic Nuclear Polarization Enhanced NMR: The AsymPol Family. J. Am. Chem. Soc. 2018, 140 (35), 11013-11019.

(60) Mathies, G.; Caporini, M. A.; Michaelis, V. K.; Liu, Y. P.; Hu, K. N.; Mance, D.; Zweier, J. L.; Rosay, M.; Baldus, M.; Griffin, R. G. Efficient Dynamic Nuclear Polarization at $800 \mathrm{MHz} / 527 \mathrm{GHz}$ with Trityl-Nitroxide Biradicals. Angew. Chem., Int. Ed. 2015, 54 (40), 11770-11774.

(61) Lund, A.; Casano, G.; Menzildjian, G.; Kaushik, M.; Stevanato, G.; Yulikov, M.; Jabbour, R.; Wisser, D.; Renom-Carrasco, M.; Thieuleux, C.; Bernada, F.; Karoui, H.; Siri, D.; Rosay, M.; Sergeyev, I. V.; Gajan, D.; Lelli, M.; Emsley, L.; Ouari, O.; Lesage, A. TinyPols: a family of water-soluble binitroxides tailored for dynamic nuclear polarization enhanced NMR spectroscopy at 18.8 and $21.1 \mathrm{~T}$. Chem. Sci. 2020, 11 (10), 2810-2818.

(62) Hu, K. N.; Bajaj, V. S.; Rosay, M.; Griffin, R. G. High-frequency dynamic nuclear polarization using mixtures of TEMPO and trityl radicals. J. Chem. Phys. 2007, 126 (4), 044512.

(63) Mentink-Vigier, F.; Mathies, G.; Liu, Y. P.; Barra, A. L.; Caporini, M. A.; Lee, D.; Hediger, S.; Griffin, R. G.; De Paepe, G. Efficient cross-effect dynamic nuclear polarization without depolarization in high-resolution MAS NMR. Chem. Sci. 2017, 8 (12), 81508163.

(64) Corzilius, B.; Smith, A. A.; Barnes, A. B.; Luchinat, C.; Bertini, I.; Griffin, R. G. High-Field Dynamic Nuclear Polarization with HighSpin Transition Metal Ions. J. Am. Chem. Soc. 2011, 133 (15), 56485651.

(65) Stevanato, G.; Kubicki, D. J.; Menzildjian, G.; Chauvin, A. S.; Keller, K.; Yulikov, M.; Jeschke, G.; Mazzanti, M.; Emsley, L. A Factor Two Improvement in High-Field Dynamic Nuclear Polarization from Gd(III) Complexes by Design. J. Am. Chem. Soc. 2019, 141 (22), $8746-8751$.

(66) Sauvee, C.; Rosay, M.; Casano, G.; Aussenac, F.; Weber, R. T.; Ouari, O.; Tordo, P. Highly Efficient, Water-Soluble Polarizing Agents for Dynamic Nuclear Polarization at High Frequency. Angew. Chem., Int. Ed. 2013, 52 (41), 10858-10861.

(67) Thurber, K. R.; Tycko, R. Perturbation of nuclear spin polarizations in solid state NMR of nitroxide-doped samples by magic-angle spinning without microwaves. J. Chem. Phys. 2014, 140 (18), 184201.

(68) Rossini, A. J.; Zagdoun, A.; Lelli, M.; Gajan, D.; Rascon, F.; Rosay, M.; Maas, W. E.; Coperet, C.; Lesage, A.; Emsley, L. One hundred fold overall sensitivity enhancements for Silicon-29 NMR spectroscopy of surfaces by dynamic nuclear polarization with CPMG acquisition. Chem. Sci. 2012, 3 (1), 108-115.

(69) Bouleau, E.; Saint-Bonnet, P.; Mentink-Vigier, F.; Takahashi, H.; Jacquot, J. F.; Bardet, M.; Aussenac, F.; Purea, A.; Engelke, F.; Hediger, S.; Lee, D.; De Paepe, G. Pushing NMR sensitivity limits 
using dynamic nuclear polarization with closed-loop cryogenic helium sample spinning. Chem. Sci. 2015, 6 (12), 6806-6812.

(70) Kubicki, D. J.; Rossini, A. J.; Purea, A.; Zagdoun, A.; Ouari, O.; Tordo, P.; Engelke, F.; Lesage, A.; Emsley, L. Amplifying dynamic nuclear polarization of frozen solutions by incorporating dielectric particles. J. Am. Chem. Soc. 2014, 136, 15711-15718.

(71) Hu, K. N.; Yu, H. H.; Swager, T. M.; Griffin, R. G. Dynamic nuclear polarization with biradicals. J. Am. Chem. Soc. 2004, 126 (35), 10844-10845.

(72) Matsuki, Y.; Maly, T.; Ouari, O.; Karoui, H.; Le Moigne, F.; Rizzato, E.; Lyubenova, S.; Herzfeld, J.; Prisner, T.; Tordo, P.; Griffin, R. G. Dynamic Nuclear Polarization with a Rigid Biradical. Angew. Chem., Int. Ed. 2009, 48 (27), 4996-5000.

(73) Mentink-Vigier, F. Optimizing nitroxide biradicals for crosseffect MAS-DNP: the role of g-tensors' distance. Phys. Chem. Chem. Phys. 2020, 22, 3643-3652.

(74) Zagdoun, A.; Casano, G.; Ouari, O.; Lapadula, G.; Rossini, A. J.; Lelli, M.; Baffert, M.; Gajan, D.; Veyre, L.; Maas, W. E.; Rosay, M.; Weber, R. T.; Thieuleux, C.; Coperet, C.; Lesage, A.; Tordo, P.; Emsley, L. A Slowly Relaxing Rigid Biradical for Efficient Dynamic Nuclear Polarization Surface-Enhanced NMR Spectroscopy: Expeditious Characterization of Functional Group Manipulation in Hybrid Materials. J. Am. Chem. Soc. 2012, 134 (4), 2284-2291.

(75) Zagdoun, A.; Rossini, A. J.; Conley, M. P.; Gruning, W. R.; Schwarzwalder, M.; Lelli, M.; Franks, W. T.; Oschkinat, H.; Coperet, C.; Emsley, L.; Lesage, A. Improved Dynamic Nuclear Polarization Surface-Enhanced NMR Spectroscopy through Controlled Incorporation of Deuterated Functional Groups. Angew. Chem., Int. Ed. 2013, 52 (4), 1222-1225.

(76) Can, T. V.; Ni, Q. Z.; Griffin, R. G. Mechanisms of dynamic nuclear polarization in insulating solids. J. Magn. Reson. 2015, 253, 23-35.

(77) Gerfen, G. J.; Becerra, L. R.; Hall, D. A.; Griffin, R. G.; Temkin, R. J.; Singel, D. J. High-Frequency (140 Ghz) Dynamic NuclearPolarization - Polarization Transfer to a Solute in Frozen AqueousSolution. J. Chem. Phys. 1995, 102 (24), 9494-9497.

(78) Dane, E. L.; Corzilius, B.; Rizzato, E.; Stocker, P.; Maly, T.; Smith, A. A.; Griffin, R. G.; Ouari, O.; Tordo, P.; Swager, T. M. Rigid Orthogonal Bis-TEMPO Biradicals with Improved Solubility for Dynamic Nuclear Polarization. J. Org. Chem. 2012, 77 (4), 17891797.

(79) Zagdoun, A.; Rossini, A. J.; Gajan, D.; Bourdolle, A.; Ouari, O.; Rosay, M.; Maas, W. E.; Tordo, P.; Lelli, M.; Emsley, L.; Lesage, A.; Coperet, C. Non-aqueous solvents for DNP surface enhanced NMR spectroscopy. Chem. Commun. 2012, 48 (5), 654-656.

(80) Pines, A.; Waugh, J. S.; Gibby, M. G. Proton-Enhanced Nuclear Induction Spectroscopy - Method for High-Resolution Nmr of Dilute Spins in Solids. J. Chem. Phys. 1972, 56 (4), 1776-1777.

(81) Peersen, O. B.; Wu, X. L.; Kustanovich, I.; Smith, S. O. Variable-Amplitude Cross-Polarization Mas Nmr. J. Magn. Reson., Ser. A 1993, 104 (3), 334-339.

(82) Volkov, A.; Dockter, C.; Bund, T.; Paulsen, H.; Jeschke, G. Pulsed EPR Determination of Water Accessibility to Spin-Labeled Amino Acid Residues in LHCIIb. Biophys. J. 2009, 96 (3), 11241141.

(83) Carmieli, R.; Papo, N.; Zimmermann, H.; Potapov, A.; Shai, Y.; Goldfarb, D. Utilizing ESEEM spectroscopy to locate the position of specific regions of membrane-active peptides within model membranes. Biophys. J. 2006, 90 (2), 492-505.

(84) Kubicki, D. J.; Rossini, A. J.; Purea, A.; Zagdoun, A.; Ouari, O.; Tordo, P.; Engelke, F.; Lesage, A.; Emsley, L. Amplifying Dynamic Nuclear Polarization of Frozen Solutions by Incorporating Dielectric Particles. J. Am. Chem. Soc. 2014, 136 (44), 15711-15718.

(85) Mentink-Vigier, F.; Paul, S.; Lee, D.; Feintuch, A.; Hediger, S.; Vega, S.; De Paepe, G. Nuclear depolarization and absolute sensitivity in magic-angle spinning cross effect dynamic nuclear polarization. Phys. Chem. Chem. Phys. 2015, 17 (34), 21824-21836.
(86) Equbal, A.; Tagami, K.; Han, S. Balancing dipolar and exchange coupling in biradicals to maximize cross effect dynamic nuclear polarization. Phys. Chem. Chem. Phys. 2020, 22 (24), 13569-13579.

(87) Hu, K. N.; Song, C.; Yu, H. H.; Swager, T. M.; Griffin, R. G. High-frequency dynamic nuclear polarization using biradicals: A multifrequency EPR lineshape analysis. J. Chem. Phys. 2008, 128 (5), 052302 .

(88) Narasimhan, S.; Scherpe, S.; Paioni, A. L.; van der Zwan, J.; Folkers, G. E.; Ovaa, H.; Baldus, M. DNP-Supported Solid-State NMR Spectroscopy of Proteins Inside Mammalian Cells. Angew. Chem., Int. Ed. 2019, 58 (37), 12969-12973.

(89) Sato, H.; Kathirvelu, V.; Fielding, A.; Blinco, J. P.; Micallef, A. S.; Bottle, S. E.; Eaton, S. S.; Eaton, G. R. Impact of molecular size on electron spin relaxation rates of nitroxyl radicals in glassy solvents between 100 and 300K. Mol. Phys. 2007, 105 (15-16), 2137-2151.

(90) Daube, D.; Aladin, V.; Heiliger, J.; Wittmann, J. J.; Barthelmes, D.; Bengs, C.; Schwalbe, H.; Corzilius, B. Heteronuclear CrossRelaxation under Solid-State Dynamic Nuclear Polarization. J. Am. Chem. Soc. 2016, 138 (51), 16572-16575.

(91) Aladin, V.; Corzilius, B. Methyl dynamics in amino acids modulate heteronuclear cross relaxation in the solid state under MAS DNP. Solid State Nucl. Magn. Reson. 2019, 99, 27-35.

(92) Meier, B.; Dumez, J.-N.; Stevanato, G.; Hill-Cousins, J. T.; Roy, S. S.; Håkansson, P.; Mamone, S.; Brown, R. C. D.; Pileio, G.; Levitt, M. H. Long-lived nuclear spin states in methyl groups and quantumrotor-induced polarization. J. Am. Chem. Soc. 2013, 135, 18746-9.

(93) Elliott, S. J.; Meier, B.; Vuichoud, B.; Stevanato, G.; Brown, L. J.; Alonso-Valdesueiro, J.; Emsley, L.; Jannin, S.; Levitt, M. H. Hyperpolarized long-lived nuclear spin states in monodeuterated methyl groups. Phys. Chem. Chem. Phys. 2018, 20, 9755-9759.

(94) Tan, K. O.; Mardini, M.; Yang, C.; Ardenkjaer-Larsen, J. H.; Griffin, R. G. Three-spin solid effect and the spin diffusion barrier in amorphous solids. Sci. Adv. 2019, 5 (7), eaax2743. 